\title{
Translating Unconventional T Cells and Their Roles in Leukemia Antitumor Immunity
}

\author{
Nilberto Dias de Araújo, ${ }^{1,2}$ Fábio Magalhães Gama, ${ }^{1,2}$ Mateus de Souza Barros $\mathbb{D}^{2}{ }^{2}$ \\ Thaís Lohana Pereira Ribeiro, ${ }^{2}$ Fabíola Silva Alves, ${ }^{2,3}$ Lilyane Amorim Xabregas, ${ }^{2,3}$ \\ Andréa Monteiro Tarragô,, ${ }^{1,2,3}$ Adriana Malheiro, ${ }^{1,2,3,4}$ and Allyson Guimarães Costa $\mathbb{D}^{1,2,3,4,5}$ \\ ${ }^{1}$ Programa de Pós-Graduação em Imunologia Básica e Aplicada, Universidade Federal do Amazonas (UFAM), Manaus, \\ AM 69067-005, Brazil \\ ${ }^{2}$ Diretoria de Ensino e Pesquisa, Fundação Hospitalar de Hematologia e Hemoterapia do Amazonas (HEMOAM), Manaus, \\ AM 69050-001, Brazil \\ ${ }^{3}$ Programa de Pós-Graduação em Ciências Aplicadas à Hematologia, Universidade do Estado do Amazonas (UEA), Manaus, \\ AM 69850-000, Brazil \\ ${ }^{4}$ Programa de Pós-Graduação em Medicina Tropical, Universidade do Estado do Amazonas (UEA), Manaus, AM 69850-000, Brazil \\ ${ }^{5}$ Instituto de Pesquisa Clínica Carlos Borborema, Fundação de Medicina Tropical Doutor Heitor Vieira Dourado (FMT-HVD), \\ Manaus, AM 69040-000, Brazil
}

Correspondence should be addressed to Allyson Guimarães Costa; allyson.gui.costa@gmail.com

Received 7 November 2020; Revised 16 December 2020; Accepted 23 December 2020; Published 7 January 2021

Academic Editor: Xue-Li Zhang

Copyright ( 2021 Nilberto Dias de Araújo et al. This is an open access article distributed under the Creative Commons Attribution License, which permits unrestricted use, distribution, and reproduction in any medium, provided the original work is properly cited.

Recently, cell-mediated immune response in malignant neoplasms has become the focus in immunotherapy against cancer. However, in leukemia, most studies on the cytotoxic potential of T cells have concentrated only on T cells that recognize peptide antigens (Ag) presented by polymorphic molecules of the major histocompatibility complex (MHC). This ignores the great potential of unconventional $\mathrm{T}$ cell populations, which include gamma-delta $\mathrm{T}$ cells $(\gamma \delta)$, natural killer $\mathrm{T}$ cells $(\mathrm{NKT})$, and mucosal-associated invariant $\mathrm{T}$ cells (MAIT). Collectively, these $\mathrm{T}$ cell populations can recognize lipid antigens, specially modified peptides and small molecule metabolites, in addition to having several other advantages, which can provide more effective applications in cancer immunotherapy. In recent years, these cell populations have been associated with a repertoire of anti- or protumor responses and play important roles in the dynamics of solid tumors and hematological malignancies, thus, encouraging the development of new investigations in the area. This review focuses on the current knowledge regarding the role of unconventional $\mathrm{T}$ cell populations in the antitumor immune response in leukemia and discusses why further studies on the immunotherapeutic potential of these cells are needed.

\section{Introduction}

Leukemia comprises a heterogeneous group of hematological neoplasms, which can be classified into lymphoblastic or myeloid leukemias and divided into acute and chronic types, depending on the affected cell type, maturation stage, and blast count, respectively [1]. While acute leukemias are characterized by a deep block in hematopoietic differentiation and result in an overproduction of immature blasts, chronic leukemias are characterized by the excessive production of partially mature differentiated cells, for example, lymphocytes in chronic lymphocytic leukemia (CLL) and granulocytes in chronic myeloid leukemia (CML) $[2,3]$. The hallmark of these neoplasms is the increase in leukemic cells (LCs) in the bone marrow (BM) and their release in the peripheral blood $(\mathrm{PB})$ and in extramedullary sites [1].

The immunological mechanisms in patients with leukemia are not very well known. However, with the increasing 
TABLE 1: The table indicates some functions triggered by unconventional $\mathrm{T}$ cells in the immune response against the tumor.

\begin{tabular}{|c|c|c|}
\hline Subsets & Role played in the immune response against cancer cells & Reference \\
\hline \multirow{7}{*}{$\gamma \delta \mathrm{T}$ cells } & Mediate tumor regression by recognizing MIC-A/MIC-B and ULBPs through TCR and NKG2D & {$[34,35,51,52,90]$} \\
\hline & Antitumor potential increased by expression of NCRs & [36] \\
\hline & Positive regulation of pAgs in LCs mediates the immune response through $\gamma \delta$ TCR & {$[40,41,72]$} \\
\hline & BTN3A/BTN2A1 increases the antitumor functions of $\gamma \delta \mathrm{T}$ cells in blood & [72-74] \\
\hline & Mediate tumor regression by recognizing PVR and nectin- 2 through TCR and DNAM-1 & [41] \\
\hline & BTN3A-expressing LCs are recognized and destroyed by $\gamma \delta \mathrm{T}$ cells in blood through TCR & [69] \\
\hline & Induce the maturation of DCs, which consequently enhance their activity against LCs & {$[29,30]$} \\
\hline \multirow{4}{*}{ NKT cells } & Mediates tumor regression by recognizing $\mathrm{CD} \mathrm{d}^{+} \mathrm{LCs}$ through TCR & [133] \\
\hline & Induces direct destruction of tumor cells through granulysin & {$[124,125]$} \\
\hline & Induces direct tumor lysis through FasL & [111] \\
\hline & They act in the immunovigilance during the initial phase of the neoplastic process & [131-134] \\
\hline MAIT cells & Induces direct cytotoxicity mediated by granzyme B and perforin in cancer cells that express MR1 & {$[162,175]$} \\
\hline
\end{tabular}

advances in the field of immunotherapy, there has been great progress in research regarding the tumor microenvironment in leukemia. Studies have shown that LCs secrete factors that disrupt healthy BM niches, reprogramming and transforming them into "leukemic niches," as well as inducing a disruption in balanced cytokine production, and favoring leukemic persistence and metastatic potential $[4,5]$. However, despite the protumor microenvironment created by LCs, studies have reported that a specific immune response can be triggered and, therefore, contribute to the defense against the tumor, although not sufficient enough to control the neoplasia [6].

Several studies have described the immunotherapeutic potential of CD8 and CD4 T cells that recognize peptide antigens (Ag) presented by polymorphic major histocompatibility complex (MHC) class I and MHC class II molecules, respectively $[7,8]$. Leaving aside, the populations of $\mathrm{T}$ cells are considered "unconventional," which are also implicated in tumor immunity, although their role in them is not well understood. Collectively, these $\mathrm{T}$ cell populations differ from their conventional counterparts mainly in the way they recognize and respond to foreign molecules. Unlike MHC-reactive $\mathrm{T}$ cells, unconventional T cells generally show simplified patterns of the T cell antigen receptor (TCR) expression and usually target monomorphic Ag-presenting molecules and other ligands, where after their activation, they promote rapid and strong effector responses $[9,10]$. These $\mathrm{T}$ cell populations include $\gamma \delta$ T cells, NKT cells, and MAIT cells.

In this review, we describe the main characteristics of these $\mathrm{T}$ cell populations and explore their activities during the neoplastic process, as well as their relationship with the establishment of an antitumor immune response or tumor-favorable response, as described briefly in Table 1 . A better understanding of the participation of these underexplored cells in tumor dynamics may provide a basis for the development of potential immunotherapeutic strategies in the field of leukemias.

\section{Subsets of Unconventional T Cells in Antileukemic Response}

2.1. Gamma-Delta $(\gamma \delta) \mathrm{T}$ Cells. $\gamma \delta \mathrm{T}$ cells are developed in the thymus during lymphopoiesis and, by the expression of the TCR (T-cell receptor), composed of gamma $(\gamma)$ and delta $(\delta)$ chains [11]. These cells are capable of providing a potent and lasting immune response through innate and adaptive mechanisms and stand out for their recognition and destruction of several tumors, regardless of major histocompatibility complex (MHC) expression [12]. In addition, these cells constitute up to $10 \%$ of circulating $\mathrm{CD}^{+}$cells and are classified according to the genetic rearrangements of the $\delta$ chain of the TCR into three main subsets: $\mathrm{V} \delta 1, \mathrm{~V} \delta 2$, and $\mathrm{V} \delta 3$ (in humans) [13]. These lymphocytes are present in blood circulation, tissues, and mucosal membranes, which are strategic places to exercise their high cytotoxic power against infections and tumors [14].

$\gamma \delta \mathrm{T}$ cell lineage is evolutionarily conserved and has several pleiotropic functions. While these cells are naturally specialized in the secretion of proinflammatory mediators (Figure 1) [15], these lymphocytes can also adopt Th2-, Th9-, and Th17-like response phenotypes [16-18]. In the tumor microenvironment (TME), these lymphocytes express a diverse repertoire of recognition receptors that have received favorable prognostic value in several malignancies, including leukemia [19]. Based on several reports, it has been confirmed that $\gamma \delta$ T cells are capable of triggering an immune response by direct and indirect mechanisms, for example, through the cytolytic synapse with the target cell, and the recruitment and stimulation of other immune cells necessary for the establishment of an antitumor response [12, 20].

These lymphocytes can induce neoplastic regression through cell-cell interaction or by secreting several soluble molecules (such as IFN- $\gamma$ and TNF) that inhibit tumor expansion. These effector molecules induce an increase in the antitumor activity of other cytotoxic cells or positively regulate the expression of MHC-I by cancer cells [21]. In addition, $\gamma \delta \mathrm{T}$ cells stimulate somatic hypermutation and isotype switching in B cells [22-24] and possibly induce antibody-mediated immunity. Their effector functions also include the activation of macrophages and the recruitment and activation of $\mathrm{CD}^{+}$cytotoxic $\mathrm{T}$ cells and NK cells [25-28]. The immune role of these lymphocytes also includes stimulating the maturation of dendritic cells (DCs), and, in turn, DCs are able to potentiate their cytotoxic activity 


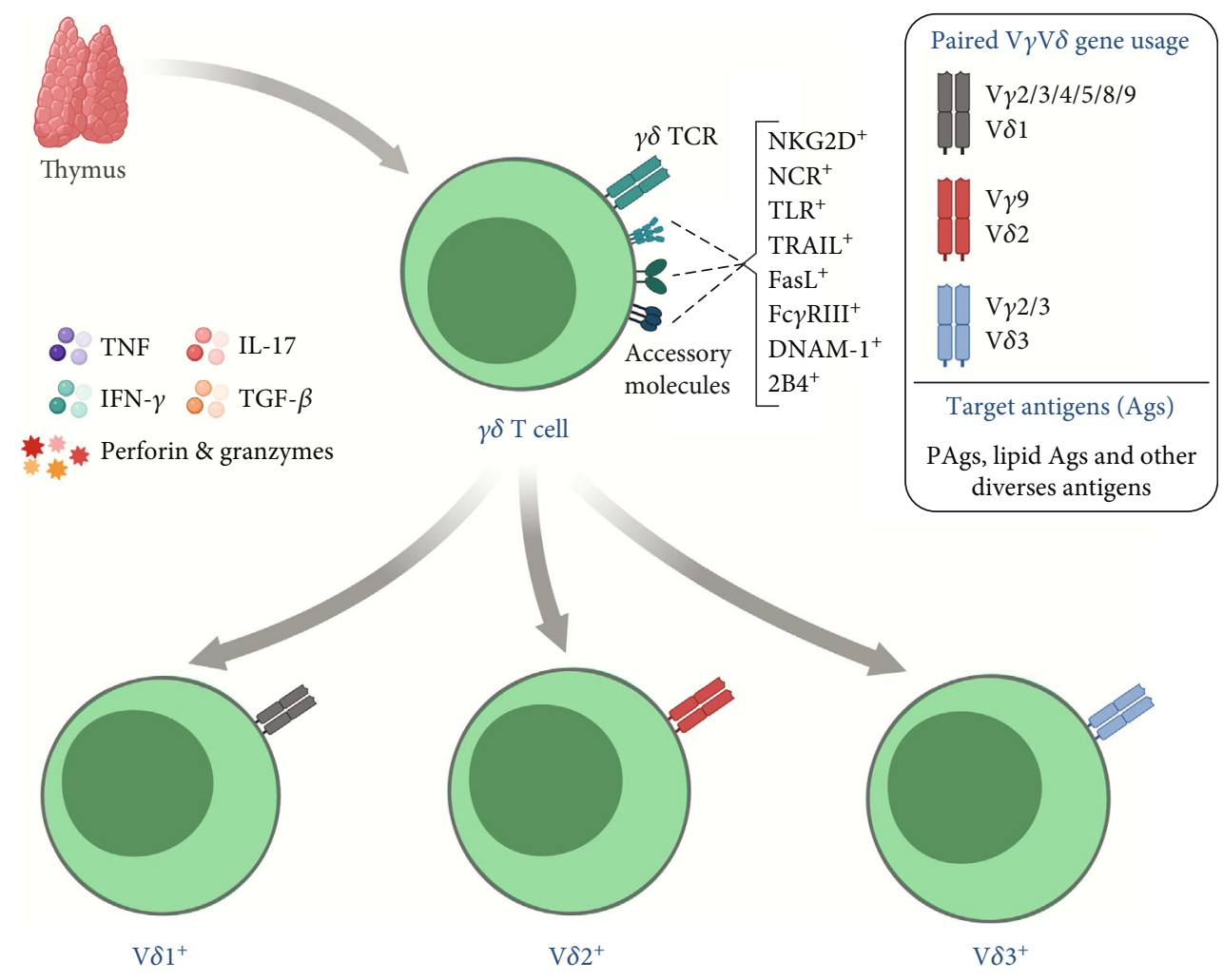

Figure 1: Overview of subpopulations, important receptors, and cytokines produced by $\gamma \delta$ T cells. $\gamma \delta$ T cells express some receptors that are essential for the tumor recognition and destruction, which gives a certain advantage when compared to other conventional T lymphocyte populations, either due to MHC independence or due to the high expression of the receptors mentioned in the image. The antileukemic recognition repertoire includes several molecules, such as NKG2D, NCRs, FasL, CD16, DNAM-1, and the TCR $\gamma \delta$ itself.

$[29,30]$. Notably, cancer cells tend to express several stressinduced molecules or metabolic antigens that are recognized through $\gamma \delta$ TCRs and accessory receptors, thereby, mediating a potent response against the tumor [31-34].

Without restrictions on MHC expression, $\gamma \delta \mathrm{T}$ cells recognize several antigens that are expressed in LCs, and generally include metabolic molecules and stress-induced molecules [32, 35-38]. Ligands, such as MIC-A/MIC-B and ULBPs, can be identified through the NKG2D receptor, which is expressed mainly in $\gamma \delta$ T cells $[34,39]$. Furthermore, some metabolites of the mevalonate pathway, known as phosphoantigens (pAgs), can be recognized directly through the TCRs and are highly regulated in LCs $[40,41]$. In addition, other molecules assist in tumor recognition and possibly support the antileukemic response of $\gamma \delta \mathrm{T}$ cells, such as TLRs (toll-like receptors), DNAM-1 (DNAX Accessory Molecule-1), FasL (Fas ligand), Fc $\gamma$ RIII, TRAIL (TNF-related apoptosis-inducing ligand), NCRs (Natural Cytotoxicity Receptors) such as NKp30, NKp44, and NKp46, and the 2B4 receptor [12, 36, 41-44].

$\mathrm{V} \delta 1^{+}$cells, which express TCR chains $\mathrm{V} \gamma 1$ to $\mathrm{V} \gamma 11$, respond preferentially in skin tissues, intestinal epithelium, lung, spleen, and liver, where they play crucial roles in maintaining epithelial tissue $[14,45]$. It is known that these lymphocytes patrol the several tissues in search of stressed cells, derived from infections and tumorigenesis, thus, maintaining tissue homeostasis [46]. For this, the secretion of Th1 and Th17 cytokines is essential for immune surveillance [12, 47-49].

These cells, although uncommon in peripheral blood ( 10\% of blood $\gamma \delta \mathrm{T}$ cells), have a high diversity of tumor recognition and have demonstrated great potential against LCs $[36,50,51]$. Correia et al. demonstrated that $\mathrm{V} \delta 1^{+}$cells that expressed NCRs managed to destroy lymphoid and myeloid cancer cells through NKp30 and NKp44, which seemed to recognize antigens that are distinct from their classic ligands, such as the molecule B7-H6, which binds to NKp30 [36]. In the same study, the stable expression of these NCRs was associated with elevated levels of granzyme B and seemed to synergize greater cytotoxic activity against LCs [36]. Taking into account that in some leukemias, a high expression of members of the ULBP family is observed, as NKG2D ligands [52], Lança et al. demonstrated that the expression of ULBP1 in LCs is important for recognition by $\mathrm{V} \delta 1$ cells [51]. ULBP3 was confirmed by Poggi et al. who presented similar findings [52]. Therefore, the data suggest possible immunological participation of these cells and indicate a significant contribution to the antileukemic immune response.

These cells can also recognize lipid or metabolic antigens that are presented through MHC class I-like molecules, such as CD1 and MR1 $[46,53]$. These and other characteristics of $\mathrm{V} \delta 1$ cells make them potential candidates for new immunotherapeutic approaches in several human tumors, and these 
have recently been explored in several experimental trials, including some against leukemia [54-56]. Although their roles are still poorly known, we know that $\mathrm{V} \delta 1$ cells demonstrate important functions in antitumor activity, and these deserve to be highlighted since they present characteristics that are different to $\mathrm{V} \gamma 9 \mathrm{~V} \delta 2$ cells, either due to their high expression of NCRs or the nonsusceptibility to activationinduced cell death (AICD) [57-59]. The roles of this subset of $\gamma \delta$ T cells in the environment of bone marrow and peripheral blood in vivo, in the context of leukemia, still need further investigation regarding the ligands and receptors of recognition that are engaged during the immune response.

The $\mathrm{V} \delta 2^{+}$subset, which pairs exclusively with the $\mathrm{V} \gamma 9$ TCR chain, responds mainly in the blood, where it recognizes pAgs derived from bacteria and cancer cells [60]. Once activated, these lymphocytes secrete effector molecules such as IFN- $\gamma$, TNF, perforins, and granzymes and exert important cytotoxic activities in peripheral blood against pathogens and tumors $[12,61]$. These cells make up as much as $95 \%$ of blood $\gamma \delta$ T cells $[50,62-64]$ and generally respond to a wide variety of pAgs, such as IPP (isopentenyl pyrophosphate) and HMB-PP (4-hydroxy-3-methyl-but-2-enylpyrophosphate), which are intermediates of the mevalonate pathway in eukaryotes and prokaryotes [65-67]. The recognition of these pAgs occurs in the context of the butyrophilin (BTN) family of molecules, such as BTN3A1 and BTN2A1 [68-71], which can be detected in LCs, and mediates a potent immune response that can be used therapeutically [72]. These molecules can be recognized directly through the $\gamma \delta$ TCR and are capable of triggering a Th1-like response against the target cells $[73,74]$.

The mechanism for recognizing pAgs is not yet clear, although several studies have recently expanded the information about how $\gamma \delta \mathrm{T}$ cells identify these molecules. Recent reports have pointed out that pAgs recognition is mediated by BTN-like molecules, which are expressed in cancer cells $[72,75]$ and are able to modulate the responses of conventional $\alpha \beta \mathrm{T}$ cells [76-79], and most notably, of $\gamma \delta \mathrm{T}$ cells $[68-71,80,81]$. The dependent detection of pAgs by $\mathrm{V} \gamma 9 \mathrm{~V} \delta 2$ cells involves the entire structure of the TCR, which interacts with BTN molecules through the $\mathrm{V} \gamma 9$ and $\mathrm{V} \delta 2$ TCR domains. Among the various molecules that make up the BTN family, the proteins BTN3A1 and BTN2A1 synergize the presentation of pAgs to $\gamma \delta \mathrm{T}$ cells, binding directly to the TCR V $\gamma 9 \mathrm{~V} \delta 2[68,70,82,83]$.

Previously, it was thought that the unit expression of BTN3A1 performed the activation of these lymphocytes alone [84], but it is now clear that the BTN2A1 protein acts as a critical factor in the activation of $\mathrm{V} \delta 2$ cells [70]. For this to occur, it is necessary that pAgs bind to the intracellular domain (B30.2) of these proteins [85, 86]. After binding of pAgs, the intra- and extracellular domains of BTN3A1 and BTN2A1 undergo a conformational change [85-87] that allows the contact of the TCR V $\gamma 9$ chain with the BTN2A1 molecule, sending activation signals to $\gamma \delta \mathrm{T}$ cells [68]. In addition, the involvement of other molecules during the pAgs detection mechanism cannot be ignored, as recent reports suggest the molecular collaboration of $\mathrm{CDR} 3$, periplakin, and GTPase RhoB in this process $[70,88,89]$.
In addition to direct and TCR-dependent recognition, other accessory molecules possibly support the antileukemic activity of $\mathrm{V} \delta 2$ cells against LCs, such as the DNAM-1 receptor that recognizes the PVR (poliovirus receptor) and Nectin2 ligands, both expressed in LCs [41], and ULBP4 that can be recognized through NKG2D [90]. $\gamma \delta$ T cells also express the 2B4 receptor (which recognizes the CD48 ligand), an accessory molecule that strengthens target effector interactions and is possibly related to increased cytotoxic activity against cancer cells [44]. One disadvantage of these $V \delta 2^{+}$cells is their strong propensity for AICD upon prolonged exposure to antigens and the polarization of these lymphocytes towards a tumor-promoting phenotype, which limits the persistence and efficiency of the immune response [57, 59].

Little data is available regarding the receptors and ligands involved in the events of innate and adaptive immunity mediated by $\mathrm{V} \delta 3^{+}$cells, which express the TCR chains $\mathrm{V} \gamma 2$, $\mathrm{V} \gamma 3$, or $\mathrm{V} \gamma 8$ and are a specific subset that responds mainly in the liver $[91,92]$. The frequency of this cell population is low in peripheral blood $(\sim 0.2 \%$ of total circulating $\mathrm{T}$ cells) though it is high in the liver and intestinal region [91, 92]. Studies have reported that $\mathrm{V} \delta 3^{+}$cells are related to antiviral immunity, responding efficiently against cytomegalovirus [93], Epstein-Barr virus [94], hepatitis [95], and HIV infection [64]. So far, their roles in antitumor immunity are not clear, although some reports have identified an expansion of these lymphocytes in the peripheral blood of patients with leukemia [96]. Also, V $\delta 3$ cells secrete IFN- $\gamma$, express NKG2D, Fc $\gamma$ RIII, and CD161, and appear to respond in a restricted way to CD1d, functionally resembling iNKT cells, which recognize and destroy $C D 1 d^{+}$target cells $[24,91]$. Subsequently, it was identified that these cells also respond to ANX-2 (annexin-2) [97], but their role in leukemia is still unexplored, although it has been identified that these cells expand during tumor progression [96].

$\gamma \delta \mathrm{T}$ cells have an enormous potential to regulate local immunity and remodel the tumor niche $[45,98,99]$. The evidence discussed so far suggests that these cells realize various antitumor activities through the direct identification of LCs through the $\gamma \delta$ TCR or accessory receptors and by secreting soluble effector molecules against the tumor. Despite this, emerging knowledge about the molecular and cellular interaction between these lymphocytes and cancer cells suggests that, like conventional $\alpha \beta \mathrm{T}$ cells, $\gamma \delta$ T cells may possibly not be exempt from the immunosuppression established by the TME [100-103]. However, the lack of knowledge about these cells in the leukemic microenvironment makes it difficult to elaborate larger and more comprehensive discussions about the possible crosstalk between this population of lymphocytes and the LCs in the bone marrow compartment and in extramedullary sites.

In addition, other subsets of $\gamma \delta$ T cells that express other variable TCR chains (TCR domains $\mathrm{V} \delta 5, \mathrm{~V} \delta 6$, and $\mathrm{V} \delta 8$ ) have been identified in other hematological malignancies, where, for example, these cells seemed to expand and respond to cancer cells in the blood of patients with lymphoma [104]. However, it is still unclear whether these cells respond against LCs and not have information available on the possible roles played by these $\gamma \delta \mathrm{T}$ cell subsets in 


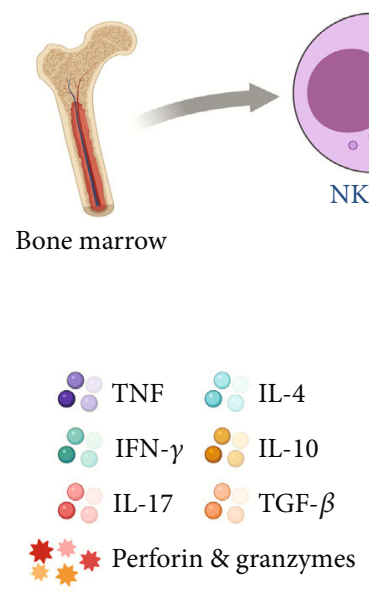

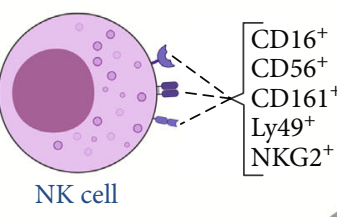
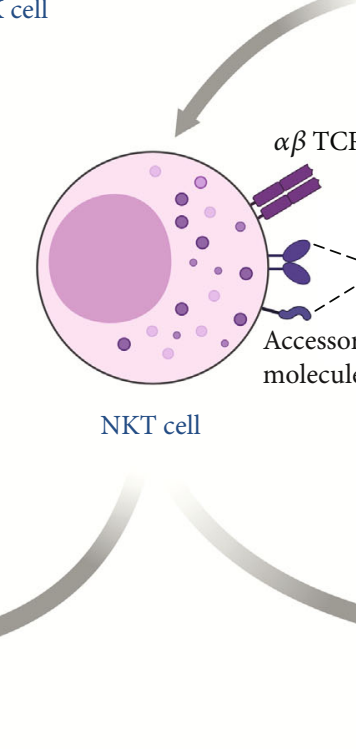
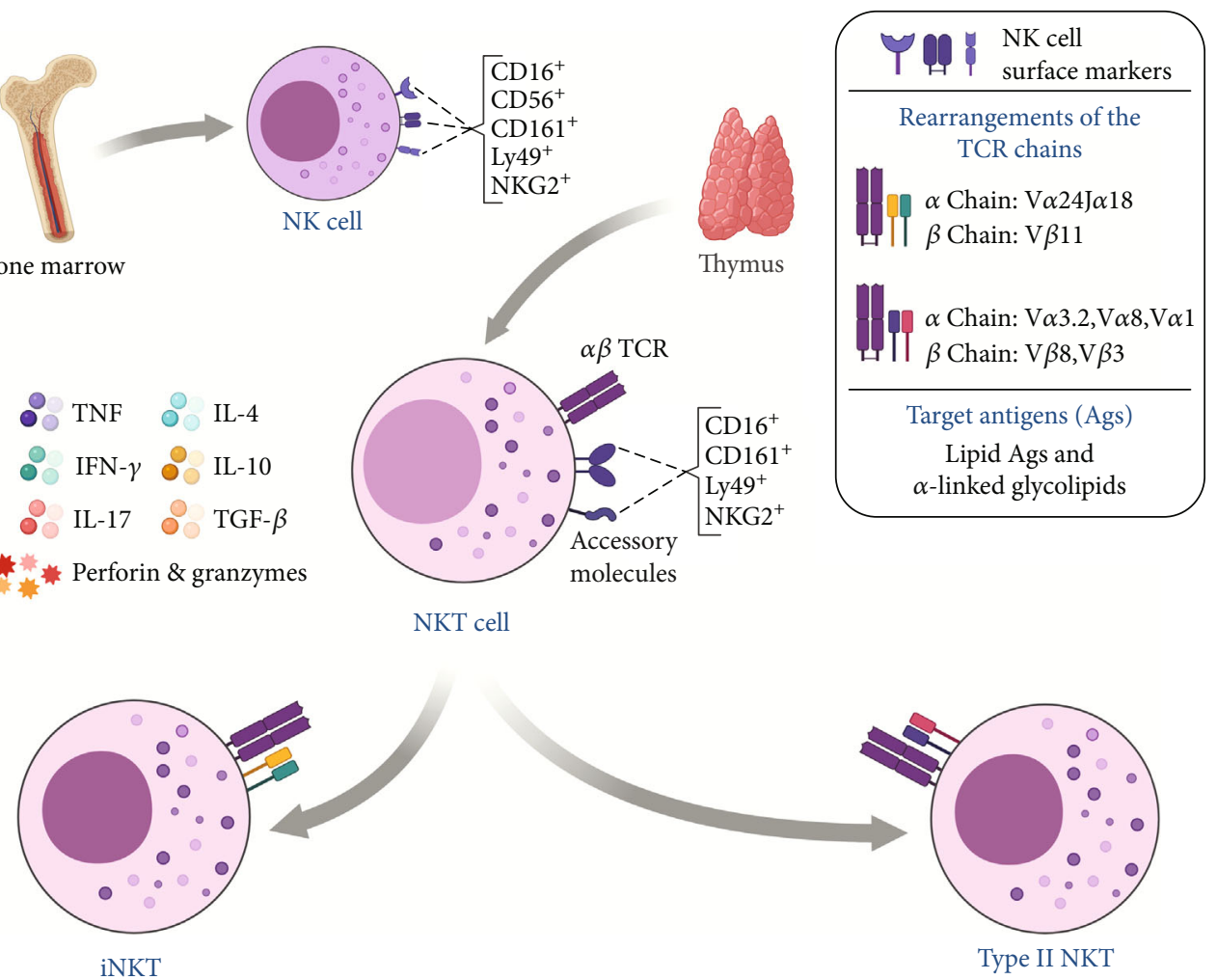

FIGURE 2: Overview of subpopulations, important receptors, and cytokines produced by NKT cells. Unlike conventional NK cells that mature in the bone marrow, NKT cells develop in the thymus and acquire an invariant or variant TCR, through which their subgroups are stratified. Recent studies show that these lymphocytes participate in the antitumor immune response by recognizing CD1d+tumors and secreting Th1, Th2, and Th17 profile cytokines.

leukemia antitumor immunity. In view of its enormous therapeutic applicability, further research is needed on the interaction of $\gamma \delta \mathrm{T}$ cells and their subsets in the leukemic microenvironment and on how this can impact the prognosis of patients.

2.2. Natural Killer T (NKT) Cells. Natural killer T cells (NKT) correspond to a population of innate-like $\mathrm{T}$ cells characterized by the expression of a TCR composed of alpha $(\alpha)$ and beta $(\beta)$ chains similar to those of conventional $\mathrm{T}$ cells, in addition to specific surface markers of natural killer cells (NK), such as $\mathrm{CD}_{16}{ }^{+}, \mathrm{CD}^{2} 6^{+}, \mathrm{CD} 9^{+}, \mathrm{CD} 161^{+}, \mathrm{NKG}_{2} \mathrm{D}^{+}$, and $\mathrm{Ly}_{49 \mathrm{~A}^{+}}[105,106]$. Another striking feature of these cells is their restriction to the CD1d molecule, which is an MHC class I-like molecule that presents lipid and glycolipid antigens [107-109].

NKT cells constitute approximately $0.001-1 \%$ of circulating lymphocytes (in humans) and are also present in the thymus, liver, intestine, and spleen [110, 111]. These cells are divided into two main subsets, the invariant natural killer $\mathrm{T}$ (iNKT) and natural killer T type II (NKTII) cells [112]. Both express the following transcription factors: T-bet $[113,114]$, PLZF [115], ROR $\gamma \mathrm{t}$, GATA-3 [114], and NF-kB [116], which together grant high cellular plasticity and allow polarization for phenotypes of profile Th1, Th2, and Th17 [116-118]. In addition, iNKTs express the LEF-1 factor $[119,120]$, which is correlated with the regulation of the expression of the gene that encodes the CD1d molecule in antigen presenting cells (APCs). The LEF-1 factor also plays a crucial role as a regulator of the Wnt pathway, and it is possible that it influences the growth, development, differentiation, and functions of NKT cells [121].

In regards to their antitumor activity, NKT cells can act directly through cell-cell interaction, through the Fas receptor and its ligand (FasL) that trigger the activation of caspase enzymes and cause apoptosis of the target cells, in addition to the interaction of other receptors such as NKG2D, TRAIL, natural cytotoxicity receptors (NCRs), and their ligands (Figure 2) $[111,113,122]$. There is also the substantial release of perforins and granzymes A and B, in addition to the production of Granulysin that act in a similar way to perforins, forming pores in the plasma membrane and altering their permeability, which results in cell lysis $[123,124]$.

NKT cells also can act through indirect mechanisms by releasing a range of mediators, especially Th1 or Th2 profile cytokines, which can vary depending on the NKT subtype, a fact that will be discussed later [125]. The release of the aforementioned mediators can results in the immunoregulation of other cells of the immune system, for example, activating or inducing the maturation of DCs through interaction with CD1d or CD40/CD40L and IFN, respectively. After activation of DCs, they will be regulated positively, expressing costimulatory molecules such as CD86 and $\mathrm{CD} 80$, in addition to release cytokines such as IL-12, a 
pleiotropic cytokine that plays an essential role in Th1-type immune response against cancer. iNKT cells also activate CD8 cytotoxic T cells through the IFN, as well as conventional NK cells and macrophages that can act against cancer cells [125-128]. In addition, NKT cells can also stimulate B lymphocytes and induce increased secretion of IgG class antibodies, which can result in antibody-dependent cell cytotoxicity (ADCC) in cancer cells that will subsequently undergo cytotoxic cell-mediated cell lysis [111, 129].

Due to their secretory repertoire and the ability to activate and target other cells of the immune system, NKT cells contribute strongly to tumor immunovigilance. It is important to highlight that one of the main forms of recognition of cancer cells by NKT cells occurs through the interaction of the TCR with the antigen presented by the CD1d molecule, expressed by B cells, macrophages, DCs, and several types of cancer cells, in solid and hematological neoplasms [116, 117]. These cells have been shown to contribute to tumor surveillance and suppression, controlling the initial stage of the neoplastic process [130-133].

iNKT cells, also known as natural killer type I cells, have characteristics that differ from other subsets, such as reactivity to $\alpha$-galactosylceramide ( $\alpha$-GalCer) and the more pronounced expression of the Th1 response profile [134]. Another characteristic of iNKT cells is related to its invariant TCR, represented in humans by a TCR- $\alpha$ chain (V $\alpha 24 \mathrm{~J} \alpha 18)$ and a TCR- $\beta$ chain (V $\beta 11)$. iNKT cells recognize lipid antigens and glycolipids such as $\alpha$-GalCer analogs, phospholipids, diacylglycerols, gangliosides (GD3), and glycosphingolipids $[107,112]$.

Studies show that iNKT cells are strongly reactive to $\alpha$ GalCer, a synthetic glycolipid derived from the marine sponge Agelas mauritianus, which is capable of inducing an important immunomodulatory effect in iNKT cells and which stimulates the antitumor response mediated by cytotoxic cells (NK cells and $\mathrm{TCD} 8^{+}$lymphocytes) that are in a state of exhaustion or anergy resulting from the TME. Stimulation mediated by iNKT cells has been shown to promote the invigoration of cytotoxic cells and reverse the dysfunction presented by these cells $[107,135]$.

The $\alpha$-GalCer antigen presented through the CD1d molecule is recognized by the TCR expressed in iNKT cells and induces the production of cytokines, such as IL-2, IL-12, and IL-21, which act on conventional NK cells and exhausted or anergic CD8 cytotoxic T cells, thus, reversing the dysfunction and the hyporesponsive character $[125,136]$. In addition, $\alpha$-GalCer-stimulated iNKT cells have been shown to incite the activation of APCs via CD40-CD40L signaling and also induce the production of IL-12 [125, 126, 129, 137].

A study by Fais et al., in patients with acute leukemia, evaluated the expression of the CD1d molecule in LCs, as well as the activity of iNKT cells in their recognition. Where, through incubating LCs with $100 \mathrm{ng} / \mathrm{ml}$ of $\alpha$-GalCer for 4 hours, it was observed that the CD1d ${ }^{+}$LCs associated with the $\alpha$-GalCer antigen underwent apoptosis induced by iNKT cells, in addition to stimulating the production of cytokines INF- $\gamma$, TNF- $\alpha$, and IL-5 [138]. Similar results were observed by Bojarska-Junak et al. in a study with BP samples from patients with chronic leukemia, in which iNKT cells stimu- lated in vitro for 24 hours with $100 \mathrm{ng} / \mathrm{ml}$ of $\alpha$-GalCer showed greater intracellular expression of the INF- $\gamma$ and IL-4 cytokines when compared with healthy volunteers. The study also pointed out that, among the two cytokines analyzed, the expression of IL-4 was greater than that of INF- $\gamma$, indicating that the iNKT cell may acquire a polarization for the Th2 response profile [139].

Another study showed that the frequency of iNKT cells was lower in patients with chronic leukemia compared to the healthy control group and that therapy for 14 days with IFN- $\gamma$ and $1 \mu \mathrm{M}$ IM (imatinib mesylate) in combination with $100 \mathrm{ng} / \mathrm{ml}$ of $\alpha$-GalCer in these patients resulted in a significant increase in iNKT cells [140]. Similarly, Weinkove et al. demonstrated that LCs purified and stimulated in vitro with $200 \mathrm{ng} / \mathrm{ml}$ of $\alpha$-GalCer for 5 days incited the proliferation of autologous and allogeneic iNKT cells, but not in a significant amount it was also demonstrated that there was a stimulation of IFN- $\gamma$ production by iNKT cells in leukemic patients. However, it was observed that the prolonged culture of these cells resulted in the polarization of iNKT cells to a Th2 profile and resulted in high levels of cytokines associated with tumor tolerance [141]. Additional investigations should be carried out to identify how stimulation with $\alpha$-GalCer can provide better results, associating the increased frequency of iNKT cells with polarization for a response profile against LCs.

Finally, in a longitudinal analysis carried out over 18 months with 22 patients that had been diagnosed with leukemia or myelodysplasia and who underwent HLA haploidentical stem cell transplantation for iNKT cell reconstitution, the existence of a correlation between the frequency of iNKT cells and disease remission was reported. The observed data showed that 14 patients whose iNKT cells were completely reconstituted showed remission, and 8 patients whose iNKT cells were not reconstituted showed recurrence, thus, associating the frequency of these cells with a better prognosis $[142,143]$. Furthermore, the analysis of the frequency of iNKT cells in the circulation and bone marrow compartment of newly diagnosed patients with acute leukemia demonstrated that a low frequency of these cells is associated with a worse prognosis [144].

Unlike iNKT cells, NKT II cells have an $\alpha \beta$ TCR variant and form diversified rearrangements. They are not reactive to $\alpha$-GalCer $[112,125,145]$; however, they are restricted to CD1d [146] and recognize antigens such as $\beta$-glucosylceramide $(\beta$-GlcCer) and sulfatide, the latter being found in the plasma membrane of myelin, in the central nervous system, in the liver, in the pancreas, and in the kidneys [147-149]. Another characteristic of the NKT II cell is related to its response profile, which is more polarized for the Th2 profile $[134,150]$.

In contrast to studies on iNKT cells, the number of studies on the role of NKT II cells in leukemia is limited. However, some studies report that NKT II can act in a negative way by contributing to the suppression of surveillance and antitumor activity and, in some situations, contributing to neoplastic progression $[111,112,151]$. Such immunosuppression is mediated through the secretion of IL-13, which activates myeloid-derived suppressor cells (MDSCs), and these, consequently, suppress the activity of tumor-infiltrating 
cytotoxic cells [150]. It is also believed that this negative regulation of NKT II in the tumor occurs due to a cross-regulation between iNKT and NKT II, where the effect of Th2 cytokines produced by NKT II cells overlap the effect by the Th1 cytokines produced by iNKT, resulting in an immunosuppressed microenvironment. In addition, it has been observed that tumors grow faster when the frequency of NKT II cells is higher than that of iNKT cells, although this suppression mechanism still needs further investigation [111, 134].

It is important to note that, in addition to NKT cells, there are other populations of nonconventional $\mathrm{T}$ cells restricted to molecules of the CD1 family, more specifically group 1, composed of CD1a, CD1b, and CD1c, which have lipid antigens or glycolipids, of microbial origin or from the organism itself [152]. Similar to NKT cells, these CD1restricted cell populations are considered an attractive target for studies in the field of cancer immunotherapy, especially in the context of hematological neoplasms, due to the diversified distribution of CD1 isotypes, where they have been shown to be expressed (CD1a, CD1b, and CD1c) in $75 \%$ of acute leukemia blasts [153].

2.3. Mucosal-Associated Invariant T (MAIT) Cells. MAIT cells correspond to a population of innate-like $\mathrm{T}$ cells and are characterized by the expression of a restricted TCR- $\alpha$ with a unique gene rearrangement pattern, namely, TRAV1-2-TRAJ33 / 12/20 (V $\alpha 7.2-J \alpha 33$ / 12/20 in humans), which pair with a limited repertoire of the TCR- $\beta$ chain, predominantly from the TRBV6 and TRBV20 gene families [154-156], and form a semi-invariant TCR restricted to nonpeptide antigens presented by MHC-related protein 1 (MR1). MR1 is a monomorphic molecule that is highly conserved throughout the evolution of mammals $[157,158]$ and is capable of presenting metabolites derived from vitamin B2 that is synthesized by a variety of microorganisms for MAIT cells $[159,160]$.

Like most T cells, MAIT cells develop in the thymus [161] and are positively selected by the cortical thymocytes $\mathrm{CD} 4^{+}$ $\mathrm{CD}^{+} \mathrm{MR}^{+}[161,162]$. After the selection process, they undergo extrathymic maturation and integrate with different tissues [163]. In humans, MAIT cells represent up to $10 \%$ of peripheral blood $\mathrm{T}$ cells and are found in abundance in mucous tissues, mesenteric lymph nodes, and liver, where they can represent up to $45 \%$ of all $\mathrm{T}$ cells $[164,165]$.

Human MAIT cells can be immunophenotyped as $\mathrm{CD}^{+}$ $\mathrm{V} \alpha 7.2^{+} \mathrm{CD} 161^{\mathrm{HI}}[166]$ and can be categorized based on the expression of CD4 and CD8 coreceptors in five subsets: $\mathrm{CD}^{+}{ }^{+} \mathrm{CD}^{-}, \mathrm{CD}^{+} \mathrm{CD}^{+}, \mathrm{CD} 4^{-} \mathrm{CD} 8^{-}, \mathrm{CD} 4^{-} \mathrm{CD} 8 \alpha \alpha^{+}$e $\mathrm{CD} 44^{-} \mathrm{CD} 8 \alpha \beta^{+}$(Figure 3); the last two $\left(\mathrm{CD} 4^{-} \mathrm{CD} 8 \alpha \alpha^{+}\right.$and CD4 $4^{-} \mathrm{CD} 8 \alpha \beta^{+}$) being the most abundant and collectively correspond to approximately $80 \%$ of MAIT cells [164]. Of note, the development of MR1 tetramers loaded with 5-OPRU [5-(2-oxopropylideneamino)-6-d-ribitylaminouracil] marked a breakthrough in MAIT cell research and have allowed for the reliable identification of distinct phenotypical and functional MAIT cell subsets [167].

In addition to the surface molecules mentioned above, MAIT cells also express CD25, CD26, CD44, and CD69, as well as IL-7R, IL-12R, IL-15R, and IL-18R cytokine receptors and PLZF, T transcription factors T-bet and ROR $\gamma \mathrm{t}$, providing high plasticity and the ability to secrete mediators of Th1 profile and/or Th17 profile [168]. It is important to note that most MAIT cells have a memory-like phenotype effector [169] and can be quickly activated by mechanisms that do not depend on TCR stimulation [170]. This is due to the high expression of various cytokine and chemokine receptors, a property they share with other innate-like T cells $(\gamma \delta$ and iNKT cells) [171].

After activation, these cells are able to release substantial quantities of perforin and granzymes, in addition to producing the proinflammatory cytokines TNF, IFN $\gamma$, and IL-17A, as well as CCL3 and CCL4, which are chemokines that are crucial for immune responses to infection and inflammation $[172,173]$. The release of these mediators results in the destruction of infected cells and the activation of other immune cells, such as DCs, which consequently leads to the mobilization of conventional $\mathrm{T}$ cells and reflects in a cascade of immunological events [174, 175].

Due to some characteristics of MAIT cells, such as their high frequency in humans and their ability to rapidly secrete a repertoire of mediators that induces activation and regulation of other cells of the immune system, in addition to the ability to recognize antigens restricted to MR1, research on MAIT cells, as well as other populations of $\mathrm{T}$ cells restricted to MR1, has aroused great interest in the field of oncology. Currently, the functional role triggered by these innate-like $T$ cells in cancer is unclear and has been the subject of several studies.

Investigations performed on patients with mucosal neoplasms have reported a reduction in the frequency of circulating MAIT cells and show a significant accumulation of these cells in the tumor tissue [176-178]. However, it is important to note that tumor-infiltrating MAIT cells were less able to produce IFN- $\gamma$ in response to factors secreted by the TME [178]. In addition, a recent in vivo study by Yan et al. showed that MAIT cells exhibited a tumorpromoting function and promoted cancer metastasis through the suppression of cytotoxic cells (which was partly IL-17 dependent) after interaction with MR1 molecules expressed on cancer cells [179].

In contrast, in the study by Won et al., tumor-infiltrating MAIT cells were not compromised in the production of cytokines IFN-y, TNF- $\alpha$, and IL-17. In addition, in the in vitro assay, it was observed that MAIT cells, isolated from PB from healthy individuals, not only had lymphokine-activated killer activity but also exhibited direct cytotoxicity in K562 cell lines through the degranulation of granzyme B and perforin [177].

To date, the involvement of MAIT cells in leukemia remains largely unexplored, and, in the context of other hematological neoplasms, the functional role of these cells is also limited. An in vitro study by Gherardin et al. demonstrated that multiple myeloma (MM) cell lines express the MR1 protein and are capable of presenting vitamin B metabolites to MAIT cells isolated from healthy donors, which, in response, induce the lysis of these myeloma cells with efficiency and kinetics similar to NK cells [164].

Another study observed the functional capacity of these lymphocytes by analyzing the cell phenotype in samples of 


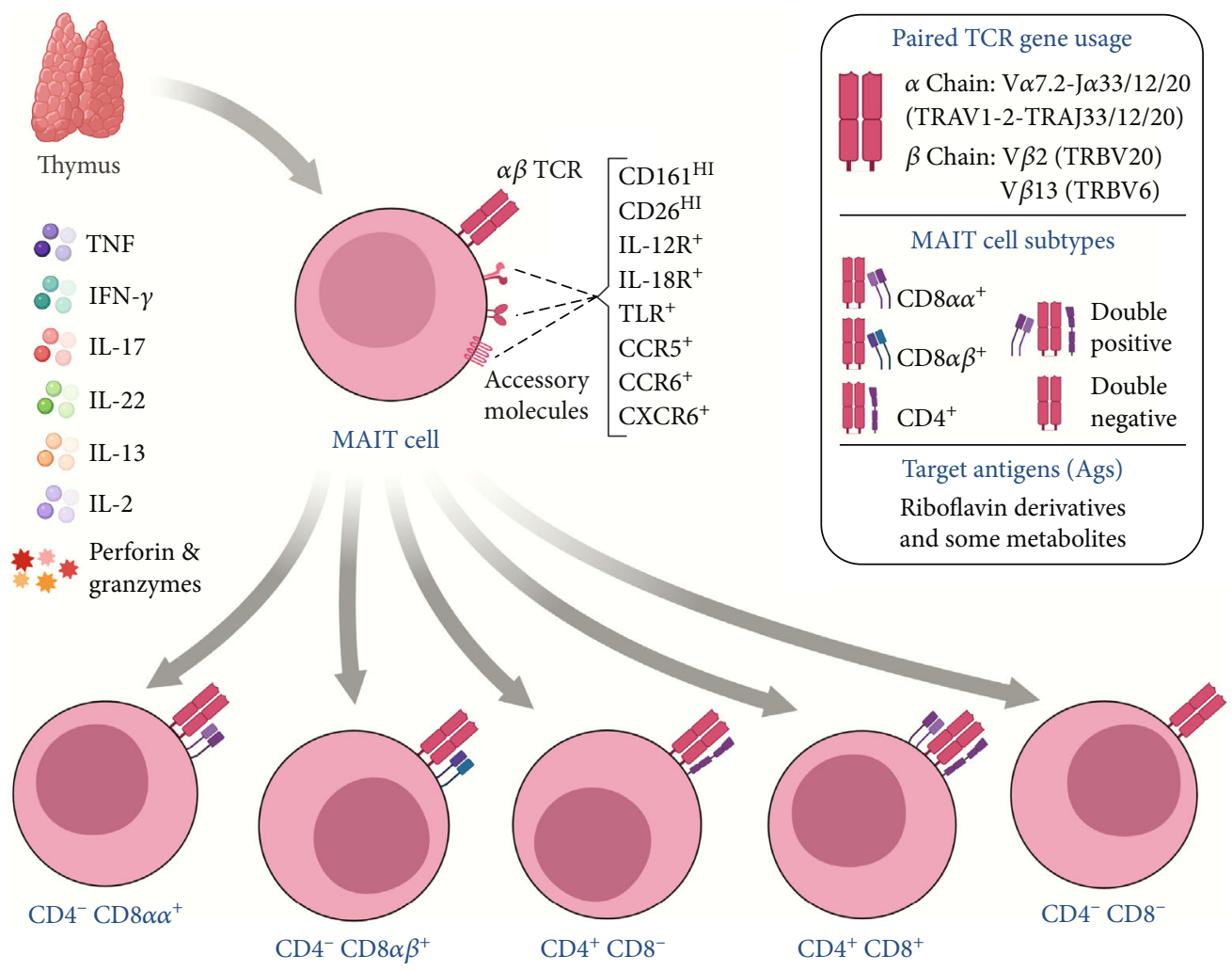

FIgURE 3: Overview of subpopulations, important receptors, and cytokines produced by MAIT cells. MAIT cells develop in the thymus, where they acquire a semi-invariant TCR, restricted to MR1. In humans, they can be categorized into five subsets based on the expression of the CD4 and $\mathrm{CD} 8$ coreceptors, with $\mathrm{CD} 4^{-} \mathrm{CD} 8 \alpha \alpha^{+}$or $\mathrm{CD} 4^{-} \mathrm{CD} 8 \alpha \beta^{+}$being the most abundant, collectively corresponding to approximately $80 \%$ of MAIT cells. They produce a repertoire of Th1 and Th17 cytokines (IFN- $\gamma$, TNF, IL-2, IL-17A, and IL-22), in addition to perforins and granzymes B, and express various cytokine, chemokine, and homing molecules.

PB and BM [180]. Favreau et al. reported that patients recently diagnosed with $\mathrm{MM}$ had a significant decrease in the frequency of MAIT cells when compared to healthy controls. They also highlighted a reduction in the MAIT CD8 ${ }^{+}$ and double-negative (CD8 ${ }^{-} \mathrm{CD}^{-}$) phenotype, in addition to the functional impairment of the Th1 response profile, with fewer IFN- $\gamma$ and TNF $\alpha$ producing MAIT cells [180]. Favreau et al. also demonstrated that circulating MAIT cells exhibited high levels of PD-1 and that their respective in vitro blockade resulted in the restoration of MAIT cell function and activation [180]. As a whole, these results highlight the important antitumor activity of MAIT cells and identify them as a potential immunotherapeutic target in MM.

Likewise, MR1 also represents an attractive target in immunotherapy against cancer, due to characteristics such as its monomorphic nature and functional expression found in several types of cancer cells [181]. In this regard, a recent study by Crowther et al. demonstrated that a human $\mathrm{T}$ cell clone potentially recognizes a specific cancer or associated metabolite, restricted to MR1, and mediates the lysis of different types of cancer cells, including LCs lineages, as such, it mediated in vivo leukemia regression and conferred longer survival in mice [182]. Moreover, other atypical MR1restricted $\mathrm{T}$ cells, which respond to autoantigens, have been described [181, 183, 184]. This new group of T cells has been named MR1T and has been shown to recognize and elimi- nate a wide range of cancer cells that express MR1 [181]. However, more research is needed to elucidate the precise nature and function of these cells, as well as their activity in the context of TME.

\section{Concluding Remarks and Perspectives}

Unconventional $\mathrm{T}$ cells can promote tumor rejection and offer advantages that indicate them as being potential targets for T-cell-based immunotherapy. Although effective, it is important to note that unconventional $\mathrm{T}$ cells are not exempt from the influence of checkpoint receptors, since these cells positively regulate the inhibitory PD1 receptor on their cell surface after activation [185-187]. However, checkpoint blockade therapy using drugs based on antiPD1 and anti-CTLA-4 is proving to be a powerful approach for preventing effector cells from entering into a state of anergy caused by cancer cells, thereby, providing a persistent immune response [188].

In the context of hematologic neoplasms, among the promising alternatives to conventional chemotherapy are the upcoming immunotherapies, in particular, the transfer of chimeric antigen receptor (CAR) T cells [189]. These autologous $\mathrm{T}$ cells, which are designed to express a CAR receptor against the CD19 antigen, are at the forefront of contemporary oncohematological therapies and lead to high 
rates of remission in B cell malignancies [190, 191]. It is important to highlight the obstacles, such as the complex and expensive individualized manufacturing process and the loss or modulation of the target CD19 antigen, that lead to resistance and relapse after therapy with CAR $\mathrm{T}$ cells.

In this scenario, unconventional $\mathrm{T}$ cells present themselves as possible solutions to overcome these obstacles, since they have a series of specific biological characteristics that can significantly expand and diversify the repertoire of CARbased therapies, although they also have their limitations [192]. Few preclinical studies have investigated unconventional $\mathrm{T}$ cells as alternative platforms for CAR engineering, and, given this limitation, it is not surprising that there is a very low number of clinical trials that evaluate the viability of CAR $\gamma \delta$ T therapies (B cell lymphoma, NCT02656147; and acute myeloid leukemia, NCT03885076) and CAR NKT (refractory B cell neoplasm, NCT03774654) in hematologic neoplasms that are in progress.

The fact is that the role of unconventional $\mathrm{T}$ cells during the neoplastic process is usually related to better immune surveillance or antitumor response in patients with leukemia, and that, to date, unconventional $\mathrm{T}$ cells are still largely underexplored. Factors, such as the absence of barriers related to histocompatibility, since the molecules that present Ag for unconventional $\mathrm{T}$ cells are monomorphic; activation by TCR dependent and independent mechanisms; ability to gather quick and powerful responses; in addition to the high frequency in specific tissues in humans, all demonstrate the need for further studies on the immunotherapeutic potential of these cells and, mainly, the translation of these studies into clinical trials.

\section{Abbreviations}

AICD: Activation-induced cell death

ALL: $\quad$ Acute lymphoblastic leukemia

AML: $\quad$ Acute myeloid leukemia

ANX-2: Annexin-2

APCs: $\quad$ Antigen-presenting cells

BM: $\quad$ Bone marrow

BTN: Butyrophilin

BTN2A1: Butyrophilin subfamily 2 member A1

BTN3A: Butyrophilin 3A

CAR: $\quad$ Chimeric antigen receptor

CD: $\quad$ Cluster of differentiation

CDR3: Complementarity-determining region-3

CTLA-4: Cytotoxic T-lymphocyte-associated antigen 4

CLL: $\quad$ Chronic lymphocytic leukemia

CML: Chronic myeloid leukemia

DCs: Dendritic cells

DNAM-1: DNAX accessory molecule-1

Fas: $\quad$ Fas Cell Surface Death Receptor

FasL: $\quad$ Fas ligand

Fc $\gamma$ RIII: $\quad$ Fc-gamma receptor type III

GM-CSF: Granulocyte-macrophage colony-stimulating factor

HIV: $\quad$ Human immunodeficiency virus

HMB-PP: (E)-4-Hydroxy-3-methyl-but-2-enyl pyrophosphate
IFN: Interferon

IL: Interleukin

iNKT: Invariant NKT

IPP: Isopentenyl pyrophosphate

LCs: Leukemic cells

MAIT: Mucosal-associated invariant T

MHC: $\quad$ Major histocompatibility complex

MIC-A: MHC class I polypeptide-related sequence A

MIC-B: $\quad$ MHC class I polypeptide-related sequence B

MM: $\quad$ Multiple myeloma

MR1: $\quad$ MHC class I-related protein

NCRs: Natural cytotoxicity receptors

NK: Natural killer

NKG2D: Natural-killer group 2 member D

NKT: $\quad$ Natural killer T

PB: $\quad$ Peripheral blood

PD1: $\quad$ Programmed cell death protein 1

pAgs: Phosphoantigens

PVR: Poliovirus receptor

TCR: T-cell receptor

TGF: Transforming growth factor

TLRs: Toll-like receptors

TME: Tumor microenvironment

TNF: $\quad$ Tumor necrosis factor

TRAIL: TNF-related apoptosis-inducing ligand

ULBP: UL16-binding protein

$\alpha$-GalCer: $\alpha$-Galactosylceramide

$\gamma \delta \mathrm{T}: \quad$ Gamma-delta T.

\section{Additional Points}

Cell-mediated immune response in malignant neoplasms is becoming the focus in immunotherapy against cancer. Unconventional $T$ cells utilize a range of receptors and proinflammatory or regulatory profiles that directly contribute to the immune response in the leukemic microenvironment. The role played by unconventional $\mathrm{T}$ cells found in the leukemic medullary microenvironment may be related to the patient's prognosis. Cytokines and chemokines secreted by unconventional T cells include IL-1 $\beta$, IL-4, IL-6, IL-10, IL13, IL-17, IL-22, IL-23, IFN- $\gamma$, TNF- $\alpha$, and TGF- $\beta$.

\section{Disclosure}

The funders had no role in study design, decision to publish, or preparation of the manuscript.

\section{Conflicts of Interest}

The authors declare that there are no conflicts of interest regarding the publication of this paper.

\section{Acknowledgments}

This study was funded by Fundação de Amparo à Pesquisa do Estado do Amazonas (FAPEAM) (Pró-Estado Program\#002/2008, PAMEQ Program-\#004/2019, and PAPAC Program-\#005/2019), Conselho Nacional de Desenvolvimento Científico e Tecnológico (CNPq), and Coordenação de 
Aperfeiçoamento de Pessoal de Nível Superior (CAPES). NDA, FMG, FSA, LAX, MSB, TLPR, and ISC received fellowships from CAPES and FAPEAM (PhD, Masters, and SI student). AM is a level 2 research fellow from $\mathrm{CNPq}$.

\section{References}

[1] A. Ehsanpour, N. Saki, M. Bagheri, M. M. Behzad, and S. Abroun, "The expression of microvesicles in leukemia: prognostic approaches," Cell Journal, vol. 21, pp. 115-123, 2018.

[2] R. A. Van Etten, "Mechanisms of transformation by the _BCR-ABL_ oncogene: new perspectives in the postimatinib era," Leukemia Research, vol. 28, pp. 21-28, 2004.

[3] R. A. Van Etten, "Aberrant cytokine signaling in leukemia," Oncogene, vol. 26, no. 47, pp. 6738-6749, 2007.

[4] F. Chiarini, A. Lonetti, C. Evangelisti et al., "Advances in understanding the acute lymphoblastic leukemia bone marrow microenvironment: from biology to therapeutic targeting," Biochimica et Biophysica Acta (BBA) - Molecular Cell Research, vol. 1863, no. 3, pp. 449-463, 2016.

[5] J. Huan, N. I. Hornick, M. J. Shurtleff et al., "RNA trafficking by acute myelogenous leukemia exosomes," Cancer Research, vol. 73, no. 2, pp. 918-929, 2013.

[6] P. Yotnda, P. Mintz, K. Grigoriadou, F. Lemonnier, E. Vilmer, and P. Langlade-Demoyen, "Analysis of T-cell defects in the specific immune response against acute lymphoblastic leukemia cells," Experimental Hematology, vol. 27, pp. 1375-1383, 1999.

[7] T. Ahrends and J. Borst, "The opposing roles of CD4+ T cells in anti-tumour immunity," Immunology, vol. 154, pp. 582592, 2018.

[8] N. R. Maimela, S. Liu, and Y. Zhang, "Fates of CD8+ T cells in tumor microenvironment," Computational and Structural Biotechnology Journal, vol. 17, pp. 1-13, 2019.

[9] D. I. Godfrey, A. P. Uldrich, J. McCluskey, J. Rossjohn, and D. B. Moody, "The burgeoning family of unconventional T cells," Nature Immunology, vol. 16, pp. 1114-1123, 2015.

[10] D. I. Godfrey, J. Le Nours, D. M. Andrews, A. P. Uldrich, and J. Rossjohn, "Cell targets for cancer immunotherapy," Immunity, vol. 48, pp. 453-473, 2018.

[11] D. G. Pellicci, H.-F. Koay, and S. P. Berzins, "Thymic development of unconventional T cells: how NKT cells, MAIT cells and $\gamma \delta$ T cells emerge," Nature Reviews Immunology, vol. 20, no. 12, pp. 756-770, 2020.

[12] Y. Zhao, C. Niu, and J. Cui, "Gamma-delta $(\gamma \delta)$ T cells: friend or foe in cancer development," Journal of Translational Medicine, vol. 16, no. 1, p. 3, 2018.

[13] C. M. Parker, V. Groh, H. Band et al., "Evidence for extrathymic changes in the T cell receptor $\gamma / \delta$ repertoire," Journal of Experimental Medicine, vol. 171, pp. 1597-1612, 1990.

[14] P. Vantourout and A. Hayday, "Six-of-the-best: unique contributions of $\gamma \delta$ T cells to immunology," Nature Reviews Immunology, vol. 13, pp. 88-100, 2013.

[15] D. Wesch, A. Glatzel, and D. Kabelitz, "Differentiation of resting human peripheral blood $\gamma \delta \mathrm{T}$ cells toward Th1- or Th2-phenotype," Cellular Immunology, vol. 212, pp. 110$117,2001$.

[16] K. J. Ness-Schwickerath, C. Jin, and C. T. Morita, "Cytokine requirements for the differentiation and expansion of IL-
17A- and IL-22-producing human V $\gamma 2 \mathrm{~V} \delta 2 \mathrm{~T}$ cells," The Journal of Immunology, vol. 184, pp. 7268-7280, 2010.

[17] N. Caccamo, C. La Mendola, V. Orlando et al., "Differentiation, phenotype, and function of interleukin-17-producing human v $\gamma 9 \mathrm{v} \delta 2$ T cells," Blood, vol. 118, pp. 129-138, 2011.

[18] C. Peters, R. Häsler, D. Wesch, and D. Kabelitz, "Human V $\delta 2$ T cells are a major source of interleukin-9," Proceedings of the National Academy of Sciences, vol. 113, pp. 12520-12525, 2016.

[19] A. J. Gentles, A. M. Newman, C. L. Liu et al., "The prognostic landscape of genes and infiltrating immune cells across human cancers," Nature Medicine, vol. 21, pp. 938-945, 2015.

[20] P. E. Lo, G. Pizzolato, A. M. Corsale et al., " $\gamma \delta$ T cells and tumor microenvironment: from immunosurveillance to tumor evasion," Frontiers in Immunology, vol. 9, 2018.

[21] Y. Gao, W. Yang, M. Pan et al., " $\gamma \delta$ T cells provide an early source of interferon $\gamma$ in tumor immunity," Journal of Experimental Medicine, vol. 198, pp. 433-442, 2003.

[22] A. A. Horner, H. Jabara, N. Ramesh, and R. S. Geha, " $\gamma / \delta$ T lymphocytes express CD40 ligand and induce isotype switching in B lymphocytes," Journal of Experimental Medicine, vol. 181, pp. 1239-1244, 1995.

[23] N. Caccamo, L. Battistini, M. Bonneville et al., "CXCR5 identifies a subset of $\mathrm{V} \gamma 9 \mathrm{~V} \delta 2 \mathrm{~T}$ cells which secrete IL-4 and IL-10 and help B cells for antibody production," The Journal of Immunology, vol. 177, pp. 5290-5295, 2006.

[24] A. Petrasca, A. M. Melo, E. P. Breen, and D. G. Doherty, "Human $\mathrm{V} \delta 3+\gamma \delta \mathrm{T}$ cells induce maturation and IgM secretion by B cells," Immunology Letters, vol. 196, pp. 126-134, 2018.

[25] M. Brandes, K. Willimann, and B. Moser, "Professional antigen-presentation function by human gd T cells," Science, vol. 309, no. 5732, pp. 264-268, 2005.

[26] M. Muto, M. Baghdadi, R. Maekawa, H. Wada, and K. I. Seino, "Myeloid molecular characteristics of human $\gamma \delta \mathrm{T}$ cells support their acquisition of tumor antigen-presenting capacity," Cancer Immunology, Immunotherapy, vol. 64, pp. 941-949, 2015.

[27] C. Mao, X. Mou, Y. Zhou et al., “Tumor-activated T cells from gastric cancer patients induce the antitumor immune response of $\mathrm{T}$ cells via their antigen-presenting cell-like effects," Journal of Immunology Research, vol. 2014, 10 pages, 2014.

[28] A. Maniar, X. Zhang, W. Lin et al., "Human $\gamma \delta$ T lymphocytes induce robust NK cell-mediated antitumor cytotoxicity through CD137 engagement," Blood, vol. 116, pp. 1726-1733, 2010.

[29] H. H. Van Acker, S. Anguille, V. F. Van Tendeloo, and E. Lion, "Empowering gamma delta T cells with antitumor immunity by dendritic cell-based immunotherapy," Oncoimmunology, vol. 4, no. 8, article e1021538, 2015.

[30] A. Martino, R. Casetti, A. Sacchi, and F. Poccia, "Central memory $\mathrm{V} \gamma 9 \mathrm{~V} \delta 2 \mathrm{~T}$ lymphocytes primed and expanded by Bacillus Calmette-Guérin-infected dendritic cells kill mycobacterial-infected monocytes," The Journal of Immunology, vol. 179, pp. 3057-3064, 2007.

[31] A. E. Simões, B. Di Lorenzo, and B. Silva-Santos, "Molecular determinants of target cell recognition by human $\gamma \delta$ T cells," Frontiers in Immunology, vol. 9, pp. 1-7, 2018.

[32] A. Q. Gomes, D. V. Correia, A. R. Grosso et al., "Identification of a panel of ten cell surface protein antigens associated 
with immunotargeting of leukemias and lymphomas by peripheral blood $\gamma \delta$ t cells," Haematologica, vol. 95, pp. 1397-1404, 2010.

[33] I. de Weerdt, S. Terpstra, T. Hofland et al., "Chronic lymphocytic leukemia (CLL) cells are susceptible to $\gamma \delta$-T cell mediated killing, provided CLL-derived $\gamma \delta$-T cell dysfunction can be reversed," Blood, vol. 126, pp. 2914-2914, 2015.

[34] S. Gundermann, E. Klinker, B. Kimmel et al., "A comprehensive analysis of primary acute myeloid leukemia identifies biomarkers predicting susceptibility to human allogeneic V $\gamma 9 \mathrm{~V} \delta 2$ T cells," Journal of Immunotherapy, vol. 37, pp. 321-330, 2014.

[35] G. M. Siegers, H. Dhamko, X.-H. Wang et al., "Human V $\delta 1$ $\gamma \delta$ T cells expanded from peripheral blood exhibit specific cytotoxicity against B-cell chronic lymphocytic leukemiaderived cells," Cytotherapy, vol. 13, pp. 753-764, 2011.

[36] D. V. Correia, M. Fogli, K. Hudspeth, M. Gomes Da Silva, D. Mavilio, and B. Silva-Santos, "Differentiation of human peripheral blood $\mathrm{V} \delta 1+\mathrm{T}$ cells expressing the natural cytotoxicity receptor NKp30 for recognition of lymphoid leukemia cells," Blood, vol. 118, pp. 992-1001, 2011.

[37] G. M. Siegers, T. C. Felizardo, A. Mark Mathieson et al., "Anti-leukemia activity of in vitro-expanded human gamma delta $\mathrm{T}$ cells in a xenogeneic Ph+leukemia model," PLoS One, vol. 6, no. 2, article e16700, 2011.

[38] G. M. Siegers, "Anti-leukemia activity of human gamma delta T cells,” Oncoimmunology, vol. 1, pp. 237-239, 2012.

[39] B. Silva-Santos and J. Strid, "Working in "NK mode": natural killer group 2 member D and natural cytotoxicity receptors in stress-surveillance by $\gamma \delta$ T cells," Frontiers in Immunology, vol. 9, p. 24, 2018.

[40] A. Pandyra, P. J. Mullen, M. Kalkat et al., "Immediate utility of two approved agents to target both the metabolic mevalonate pathway and its restorative feedback loop," Cancer Research, vol. 74, pp. 4772-4782, 2014.

[41] J. Gertner-Dardenne, R. Castellano, E. Mamessier et al., "Human $\mathrm{V} \gamma 9 \mathrm{~V} \delta 2 \mathrm{~T}$ cells specifically recognize and kill acute myeloid leukemic blasts," The Journal of Immunology, vol. 188, pp. 4701-4708, 2012.

[42] S. Kalyan, D. Wesch, and D. Kabelitz, "Aminobisphosphonates and toll-like receptor ligands: recruiting $\mathrm{V} \gamma 9 \mathrm{~V} \delta 2 \mathrm{~T}$ cells for the treatment of hematologic malignancy," Current Medicinal Chemistry, vol. 18, no. 34, pp. 5206-5216, 2011.

[43] F. Mami-Chouaib, P. Del Porto, D. Delorme, and T. Hercend, "Further evidence for a gamma/delta $\mathrm{T}$ cell receptormediated TCT.1/CD48 recognition," Journal of Immunological, vol. 147, no. 9, pp. 2864-2867, 1991.

[44] C. Flament, K. Bellagha, A. Rosenthal-Allieri, S. Chouaib, and F. Mami-Chouaib, "CD48 may serve as an accessory molecule for the activation of a subset of human $\gamma / \delta$ T cells," Human Immunology, vol. 46, pp. 82-92, 1996.

[45] D. Wu, P. Wu, F. Qiu, Q. Wei, and J. Huang, "Human $\gamma \delta$ T-cell subsets and their involvement in tumor immunity," Cellular \& Molecular Immunology, vol. 14, pp. 245253, 2017.

[46] M. S. Davey, C. R. Willcox, A. T. Baker, S. Hunter, and B. E. Willcox, "Recasting human $\mathrm{V} \delta 1$ lymphocytes in an adaptive role," Trends in Immunology, vol. 39, pp. 446459, 2018.

[47] B. Silva-Santos, K. Serre, and H. Norell, " $\gamma \delta$ T cells in cancer," Nature reviews immunology, vol. 15, pp. 683-691, 2015.
[48] Y. L. Wu, Y. P. Ding, Y. Tanaka et al., " $\gamma \delta$ T cells and their potential for immunotherapy," International Journal of Biological Sciences, vol. 10, pp. 119-135, 2014.

[49] A. G. Ramstead and M. A. Jutila, "Complex role of $\gamma \delta$ T-cellderived cytokines and growth factors in cancer," Journal of Interferon \& Cytokine Research, vol. 32, pp. 563-569, 2012.

[50] D. Kozbor, G. Trinchieri, D. S. Monos et al., "Human TCR$\gamma+/ \delta+$, CD8+ T lymphocytes recognize tetanus toxoid in an MHC-restricted fashion," Journal of Experimental Medicine, vol. 169, pp. 1847-1851, 1989.

[51] T. Lança, D. V. Correia, C. F. Moita et al., "The MHC class Ib protein ULBP1 is a nonredundant determinant of leukemia/lymphoma susceptibility to $\gamma \delta$ T-cell cytotoxicity," Blood, vol. 115, pp. 2407-2411, 2010.

[52] A. Poggi, C. Venturino, S. Catellani et al., "V $\delta 1$ T lymphocytes from B-CLL patients recognize ULBP3 expressed on leukemic B cells and up-regulated by trans-retinoic acid," Cancer Research, vol. 64, pp. 9172-9179, 2004.

[53] B. E. Willcox, F. Mohammed, and C. R. Willcox, " $\gamma \delta$ TCR recognition of MR1: adapting to life on the flip side," Trends in Biochemical Sciences, vol. 45, pp. 551-553, 2020.

[54] A. R. Almeida, D. V. Correia, A. Fernandes-Platzgummer et al., "Delta one T cells for immunotherapy of chronic lymphocytic leukemia: clinical-grade expansion/differentiation and preclinical proof of concept," Clinical Cancer Research, vol. 22, pp. 5795-5804, 2016.

[55] B. Di Lorenzo, A. E. Simões, F. Caiado et al., "Broad cytotoxic targeting of acute myeloid leukemia by polyclonal delta one $\mathrm{T}$ cells," Cancer Immunology Research, vol. 7, pp. 552-558, 2019.

[56] K. Garber, " $\gamma \delta$ T cells bring unconventional cancer-targeting to the clinic - again," Nature Biotechnology, vol. 38, pp. 389391, 2020.

[57] Y. H. Gan, S. S. N. Lui, and M. Malkovsky, "Differential susceptibility of naïve and activated human $\gamma \delta \mathrm{T}$ cells to activation-induced cell death by T-cell receptor cross-linking," Molecular Medicine, vol. 7, pp. 636-643, 2001.

[58] D. Kabelitz, "Effector functions and control of human $\gamma \delta \mathrm{T}$ cell activation," Microbes and Infection, vol. 1, pp. 255-261, 1999.

[59] P. F. Meeh, M. King, R. L. O’Brien et al., "Characterization of the $\gamma \delta \mathrm{T}$ cell response to acute leukemia," Cancer Immunology, Immunotherapy, vol. 55, pp. 1072-1080, 2006.

[60] C. R. Willcox, M. S. Davey, and B. E. Willcox, "Development and selection of the human $\mathrm{V} \gamma 9 \mathrm{~V} \delta 2+$ T-cell repertoire," Frontiers in Immunology, vol. 9, p. 1501, 2018.

[61] A. Vyborova, D. X. Beringer, D. Fasci et al., " $\gamma 9 \delta 2$ T cell diversity and the receptor interface with tumor cells," Journal of Clinical Investigation, vol. 130, no. 9, pp. 4637-4651, 2020.

[62] S. Fonseca, V. Pereira, C. Lau, M. dos Anjos Teixeira, M. BiniAntunes, and M. Lima, "Human peripheral blood gamma delta T cells: report on a series of healthy Caucasian Portuguese adults and comprehensive review of the literature," Cells, vol. 9, p. 729, 2020.

[63] T. Hinz, D. Wesch, F. Halary et al., "Identification of the complete expressed human TCR V $(\gamma)$ repertoire by flow cytometry," International Immunology, vol. 9, pp. 1065-1072, 1997.

[64] D. Kabelitz, T. Hinz, T. Dobmeyer et al., "Clonal expansion of $\mathrm{V} \gamma 3 / \mathrm{V} \delta 3$-expressing $\gamma \delta \mathrm{T}$ cells in a HIV-1/2-negative patient with CD4 T-cell deficiency," British Journal of Haematology, vol. 96, pp. 266-271, 1997. 
[65] G. Gruenbacher and M. Thurnher, "Mevalonate metabolism in immuno-oncology," Frontiers in Immunology, vol. 8, p. 1714, 2017.

[66] M. Moulin, J. Alguacil, S. Gu et al., "V $\gamma 9 \mathrm{~V} \delta 2 \mathrm{~T}$ cell activation by strongly agonistic nucleotidic phosphoantigens," Cellular and Molecular Life Sciences, vol. 74, pp. 4353-4367, 2017.

[67] T. Herrmann, A. S. Fichtner, and M. M. Karunakaran, “An update on the molecular basis of phosphoantigen recognition by V $\gamma 9$ V $\delta 2$ T cells," Cells, vol. 9, p. 1433, 2020.

[68] M. Rigau, S. Ostrouska, T. S. Fulford et al., "Butyrophilin 2A1 is essential for phosphoantigen reactivity by gd T cells," Science, vol. 367, article eaay5516, 2020.

[69] J. L. Blazquez, A. Benyamine, C. Pasero, and D. Olive, "New insights into the regulation of $\gamma \delta \mathrm{T}$ cells by BTN3A and other BTN/BTNL in tumor immunity," Frontiers in Immunology, vol. 9, pp. 1-11, 2018.

[70] M. M. Karunakaran, C. R. Willcox, M. Salim et al., "Butyrophilin-2A1 directly binds germline-encoded regions of the $\mathrm{V} \gamma 9 \mathrm{~V} \delta 2 \mathrm{TCR}$ and is essential for phosphoantigen sensing," Immunity, vol. 52, pp. 487-498.e6, 2020.

[71] C. R. Willcox, P. Vantourout, M. Salim et al., "Butyrophilinlike 3 directly binds a human $\mathrm{V} \gamma 4+\mathrm{T}$ cell receptor using a modality distinct from clonally-restricted antigen," Immunity, vol. 51, pp. 813-825.e4, 2019.

[72] A. Benyamine, A. le Roy, E. Mamessier et al., "BTN3A molecules considerably improve $\mathrm{V} \gamma 9 \mathrm{~V} \delta 2 \mathrm{~T}$ cells-based immunotherapy in acute myeloid leukemia," Oncoimmunology, vol. 5, no. 10, article e1146843, 2016.

[73] V. Lafont, J. Liautard, J. P. Liautard, and J. Favero, "Production of TNF- $\alpha$ by human $\mathrm{V} \gamma 9 \mathrm{~V} \delta 2 \mathrm{~T}$ cells via engagement of Fc $\gamma$ RIIIA, the low affinity type 3 receptor for the Fc portion of IgG, expressed upon TCR activation by nonpeptidic antigen," Journal of Immunology, vol. 166, pp. 7190-7199, 2001.

[74] A. deBarros, M. Chaves-Ferreira, F. D’Orey, J. C. Ribot, and B. Silva-Santos, "CD70-CD27 interactions provide survival and proliferative signals that regulate $\mathrm{T}$ cell receptor-driven activation of human $\gamma \delta$ peripheral blood lymphocytes," Eur J Immunol, vol. 41, pp. 195-201, 2011.

[75] E. Compte, P. Pontarotti, Y. Collette, M. Lopez, and D. Olive, "Frontline: characterization of BT3 molecules belonging to the B7 family expressed on immune cells," European Journal of Immunology, vol. 34, pp. 2089-2099, 2004.

[76] J. R. Cubillos-Ruiz, D. Martinez, U. K. Scarlett et al., "CD277 is a negative co-stimulatory molecule universally expressed by ovarian cancer microenvironmental cells," Oncotarget, vol. 1, pp. 329-338, 2010.

[77] T. Yamazaki, I. Goya, D. Graf, S. Craig, N. Martin-Orozco, and C. Dong, "A butyrophilin family member critically inhibits T cell activation," Journal of Immunology, vol. 185, pp. 5907-5914, 2010.

[78] K. Sarter, E. Leimgruber, F. Gobet et al., "Btn2a2, a T cell immunomodulatory molecule coregulated with MHC class II genes," Journal of Experimental Medicine, vol. 213, pp. 177-187, 2016.

[79] N. Messal, E. Mamessier, A. Sylvain et al., "Differential role for CD277 as a co-regulator of the immune signal in T and NK cells," European Journal of Immunology, vol. 41, pp. 3443-3454, 2011.

[80] K. K. Payne, J. A. Mine, S. Biswas et al., "BTN3A1 governs antitumor responses by coordinating ab and gd T cells," Science, vol. 369, pp. 942-949, 2020.
[81] R. D. M. Barros, N. A. Roberts, R. J. Dart et al., "Epithelia use butyrophilin-like molecules to shape organ-specific $\gamma \delta$ T cell compartments," Cell, vol. 167, pp. 203-218.e17, 2016.

[82] S. Vavassori, A. Kumar, G. S. Wan et al., "Butyrophilin 3A1 binds phosphorylated antigens and stimulates human $\gamma \delta \mathrm{T}$ cells," Nature Immunology, vol. 14, pp. 908-916, 2013.

[83] A. Sandstrom, C. M. Peigné, A. Léger et al., "The intracellular B30.2 domain of butyrophilin 3A1 binds phosphoantigens to mediate activation of human $\mathrm{V} \gamma 9 \mathrm{~V} \delta 2 \mathrm{~T}$ Cells," Immunity, vol. 40, pp. 490-500, 2014.

[84] C. Harly, Y. Guillaume, S. Nedellec et al., "Key implication of CD277/butyrophilin-3 (BTN3A) in cellular stress sensing by a major human $\gamma \delta$ T-cell subset," Blood, vol. 120, pp. 22692279, 2012.

[85] S. Gu, J. R. Sachleben, C. T. Boughter et al., "Phosphoantigeninduced conformational change of butyrophilin $3 \mathrm{~A} 1$ (BTN3A1) and its implication on $\mathrm{V} \gamma 9 \mathrm{~V} \delta 2 \mathrm{~T}$ cell activation," Proceedings of the National Academy of Sciences, vol. 114, pp. E7311-E7320, 2017.

[86] Y. Yang, L. Li, L. Yuan et al., “A structural change in butyrophilin upon phosphoantigen binding underlies phosphoantigen-mediated V $\gamma 9 \mathrm{~V} \delta 2 \mathrm{~T}$ cell activation," Immunity, vol. 50, pp. 1043-1053.e5, 2019.

[87] M. Salim, T. J. Knowles, A. T. Baker et al., "BTN3A1 discriminates $\gamma \delta \mathrm{T}$ cell phosphoantigens from nonantigenic small molecules via a conformational sensor in its B30.2 domain," ACS Chemical Biology, vol. 12, pp. 2631-2643, 2017.

[88] Z. Sebestyen, W. Scheper, A. Vyborova et al., "RhoB mediates phosphoantigen recognition by V $\gamma 9 \mathrm{~V} \delta 2$ T cell receptor," Cell Reports, vol. 15, pp. 1973-1985, 2016.

[89] D. A. Rhodes, H.-C. Chen, A. J. Price et al., "Activation of human $\gamma \delta \mathrm{T}$ cells by cytosolic interactions of BTN3A1 with soluble phosphoantigens and the cytoskeletal adaptor periplakin," Journal of Immunology, vol. 194, pp. 2390-2398, 2015.

[90] Y. Kong, W. Cao, X. Xi, C. Ma, L. Cui, and W. He, "The NKG2D ligand ULBP 4 binds to TCR $\gamma 9 / \delta 2$ and induces cytotoxicity to tumor cells through both TCR $\gamma \delta$ and NKG2D," Blood, vol. 114, pp. 310-317, 2009.

[91] B. A. Mangan, M. R. Dunne, V. P. O'Reilly et al., "Cutting edge: CD1d restriction and Th1/Th2/Th17 cytokine secretion by human V $\delta 3$ T cells," Journal of Immunology, vol. 191, pp. 30-34, 2013.

[92] T. Kenna, L. Golden-Mason, S. Norris, J. E. Hegarty, C. O'Farrelly, and D. G. Doherty, "Distinct subpopulations of $\gamma \delta$ T cells are present in normal and tumor-bearing human liver," Clinical Immunology, vol. 113, pp. 56-63, 2004.

[93] A. Knight, A. J. Madrigal, S. Grace et al., "The role of V $\delta 2-$ negative $\gamma \delta \mathrm{T}$ cells during cytomegalovirus reactivation in recipients of allogeneic stem cell transplantation," Blood, vol. 116, pp. 2164-2172, 2010.

[94] L. Farnault, J. Gertner-Dardenne, F. Gondois-Rey et al., "Clinical evidence implicating gamma-delta T cells in EBV control following cord blood transplantation," Bone Marrow Transplant, vol. 48, pp. 1478-1479, 2013.

[95] N. Rajoriya, J. Fergusson, J. A. Leithead, and P. Klenerman, "Gamma delta T-lymphocytes in hepatitis C and chronic liver disease," Frontiers in Immunology, vol. 5, pp. 1-9, 2014.

[96] J. Bartkowiak, D. Kulczyck-Wojdala, J. Z. Blonski, and T. Robak, "Molecular diversity of gammadelta $\mathrm{T}$ cells in 
peripheral blood from patients with B-cell chronic lymphocytic leukaemia,” Neoplasma, vol. 49, pp. 86-90, 2002.

[97] R. Marlin, A. Pappalardo, H. Kaminski et al., "Sensing of cell stress by human $\gamma \delta$ TCR-dependent recognition of annexin A2," Proceedings of the National Academy of Sciences, vol. 114, pp. 3163-3168, 2017.

[98] M. Rei, D. J. Pennington, and B. Silva-Santos, "The emerging protumor role of $\gamma \delta$ T lymphocytes: implications for cancer immunotherapy," Cancer Research, vol. 75, pp. 798-802, 2015.

[99] E. Lo Presti, R. Di Mitri, G. Pizzolato, F. Mocciaro, F. Dieli, and S. Meraviglia, " $\gamma \delta$ cells and tumor microenvironment: a helpful or a dangerous liason?," Journal of Leukocyte Biology, vol. 103, pp. 485-492, 2018.

[100] P. E. Lo, G. Pizzolato, E. Gulotta et al., "Current advances in $\gamma \delta$ T cell-based tumor immunotherapy," Frontiers in Immunology, vol. 8, p. 1401, 2017.

[101] U. E. Höpken and A. Rehm, "Targeting the tumor microenvironment of leukemia and lymphoma," Trends in Cancer, vol. 5, pp. 351-364, 2019.

[102] A. J. Lamble and E. F. Lind, "Targeting the immune microenvironment in acute myeloid leukemia: a focus on $\mathrm{T}$ cell immunity," Frontiers in Oncology, vol. 8, p. 213, 2018.

[103] N. Baryawno, D. Przybylski, M. S. Kowalczyk et al., "A cellular taxonomy of the bone marrow stroma in homeostasis and leukemia," Cell, vol. 177, pp. 1915-1932.e16, 2019.

[104] L. Wang, M. Xu, C. Wang et al., "The feature of distribution and clonality of tcr $\gamma / \delta$ subfamilies T cells in patients with b-cell non-Hodgkin lymphoma," Journal of Immunology Research, vol. 2014, 6 pages, 2014.

[105] A. M. Abel, C. Yang, M. S. Thakar, and S. Malarkannan, "Natural killer cells: development, maturation, and clinical utilization," Frontiers in Immunology, vol. 9, 2018.

[106] K. Benlagha, T. Kyin, A. Beavis, L. Teyton, and A. Bendelac, "A thymic precursor to the NK T cell lineage," Science, vol. 296, pp. 553-555, 2002.

[107] C.-M. Liao, M. I. Zimmer, and C.-R. Wang, "The functions of type I and type II natural killer T cells in inflammatory bowel diseases," Inflamm Bowel Dis, vol. 19, pp. 1330-1338, 2013.

[108] L. Wu, C. L. Gabriel, V. V. Parekh, and L. Van Kaer, "Invariant natural killer $\mathrm{T}$ cells: innate-like $\mathrm{T}$ cells with potent immunomodulatory activities," Tissue Antigens, vol. 73, pp. 535-545, 2009.

[109] D. I. Godfrey, H. R. MacDonald, M. Kronenberg, M. J. Smyth, and L. Van Kaer, "NKT cells: what's in a name?," Nature Reviews Immunology, vol. 4, pp. 231-237, 2004.

[110] S. P. Berzins, A. D. Cochrane, D. G. Pellicci, M. J. Smyth, and D. I. Godfrey, "Limited correlation between human thymus and blood NKT cell content revealed by an ontogeny study of paired tissue samples," European Journal of Immunology, vol. 35, pp. 1399-1407, 2005.

[111] M. Waldowska, A. Bojarska-Junak, and J. Roliński, "A brief review of clinical trials involving manipulation of invariant NKT cells as a promising approach in future cancer therapies," Central European Journal of Immunology, vol. 42, pp. 181-195, 2017.

[112] V. Kumar and T. L. Delovitch, "Different subsets of natural killer T cells may vary in their roles in health and disease," Immunology, vol. 142, pp. 321-336, 2014.

[113] M. J. Townsend, A. S. Weinmann, J. L. Matsuda et al., “T-bet regulates the terminal maturation and homeostasis of NK and V $\alpha 14$ i NKT cells," Immunity, vol. 20, pp. 477-494, 2004.

[114] J. B. Altman, A. D. Benavides, R. Das, and H. Bassiri, "Antitumor responses of invariant natural killer T cells," Journal of Immunology Research, vol. 2015, 10 pages, 2015.

[115] D. Kovalovsky, O. U. Uche, S. Eladad et al., "The BTB-zinc finger transcriptional regulator PLZF controls the development of invariant natural killer T cell effector functions," Nature Immunology, vol. 9, pp. 1055-1064, 2008.

[116] L. Van Kaer, V. V. Parekh, and L. Wu, "Invariant natural killer T cells: bridging innate and adaptive immunity," Cell Tissue Res, vol. 343, pp. 43-55, 2011.

[117] P. T. Lee, K. Benlagha, L. Teyton, and A. Bendelac, "Distinct functional lineages of human V $\alpha 24$ natural killer T cells," Journal of Experimental Medicine, vol. 195, pp. 637-641, 2002.

[118] L. Moreira-Teixeira, M. Resende, M. Coffre et al., "Proinflammatory environment dictates the IL-17 - producing capacity of human invariant NKT cells," The Journal of Immunology, vol. 186, pp. 5758-5765, 2020.

[119] H. Wang and K. A. Hogquist, "How lipid-specific T cells become effectors: the differentiation of iNKT subsets," Frontiers in Immunology, vol. 9, 2018.

[120] Q.-Y. Chen, T. Zhang, S. H. Pincus et al., "Human CD1D gene expression is regulated by LEF-1 through distal promoter regulatory elements," The Journal of Immunology, vol. 184, pp. 5047-5054, 2010.

[121] M. Haseeb, R. H. Pirzada, Q. U. Ain, and S. Choi, "Wnt signaling in the regulation of immune cell and cancer therapeutics," Cells, vol. 8, no. 11, p. 1380, 2019.

[122] F. Strati, "License to kill : when iNKT cells are granted the use of lethal cytotoxicity," International Journal of Molecular Sciences, vol. 21, pp. 1-17, 2020.

[123] C. Wu, J. Li, L. Li et al., "Extracellular vesicles derived from natural killer cells use multiple cytotoxic proteins and killing mechanisms to target cancer cells," Journal of Extracellular Vesicles, vol. 8, no. 1, 2019.

[124] E. Sparrow, "Granulysin: the attractive side of a natural born killer," Immunology Letters, vol. 217, pp. 126-132, 2020.

[125] E. A. Bae, H. Seo, I. K. Kim, I. Jeon, and C. Y. Kang, "Roles of NKT cells in cancer immunotherapy," Archives of Pharmacal Research, vol. 42, no. 7, pp. 543-548, 2019.

[126] H. Kitamura, K. Iwakabe, T. Yahata et al., "The natural killer $\mathrm{T}(\mathrm{NKT})$ cell ligand $\alpha$-galactosylceramide demonstrates its immunopotentiating effect by inducing interleukin (IL)-12 production by dendritic cells and IL-12 receptor expression on NKT cells," Journal of Experimental Medicine, vol. 189, pp. 1121-1128, 1999.

[127] H. Bassiri, R. Das, P. Guan et al., "iNKT cell cytotoxic responses control T-lymphoma growth in vitro and in vivo," Cancer Immunology Research, vol. 2, pp. 59-69, 2014.

[128] R. M. McEwen-Smith, M. Salio, and V. Cerundolo, "The regulatory role of invariant NKT cells in tumor immunity," Cancer Immunology Research, vol. 3, pp. 425-435, 2015.

[129] J. Tan, W. Xiao, L. Wang, and Y. He, “Type I natural killer T cells : naturally born for fighting," Acta Pharmacologica Sinica, vol. 31, pp. 1123-1132, 2010.

[130] E. Vivier, S. Ugolini, D. Blaise, C. Chabannon, and L. Brossay, "Targeting natural killer cells and natural killer T cells in cancer," Natural Killer Cells, vol. 12, pp. 239-252, 2012. 
[131] F. Gorini, L. Azzimonti, G. Delfanti et al., "Invariant NKT cells contribute to chronic lymphocytic leukemia surveillance and prognosis," Blood, vol. 129, pp. 3440-3451, 2017.

[132] L. S. Metelitsa, K. I. Weinberg, P. D. Emanuel, and R. C. Seeger, "Expression of CD1d by myelomonocytic leukemias provides a target for cytotoxic NKT cells," Leukemia, vol. 17, pp. 1068-1077, 2003.

[133] T. Fiedler, W. Walter, T. E. Reichert, and M. J. Maeurer, "Regulation of CD1d expression by murine tumor cells: escape from immunosurveillance or alternate target molecules?," International Journal of Cancer, vol. 98, pp. 389397, 2002.

[134] M. Terabe and J. A. Berzofsky, "NKT cells in immunoregulation of tumor immunity: a new immunoregulatory axis," Trends Immunol, vol. 28, pp. 491-496, 2007.

[135] L. Brossay, M. Chioda, N. Burdin et al., "CD1d-mediated recognition of an $\alpha$-galactosylceramide by natural killer T cells is highly conserved through mammalian evolution," Journal of Experimental Medicine, vol. 188, pp. 1521-1528, 1998.

[136] H. Seo, I. Jeon, B.-S. Kim et al., "IL-21-mediated reversal of NK cell exhaustion facilitates anti-tumour immunity in MHC class I-deficient tumours," Nature Communications, vol. 8, pp. 1-14, 2017.

[137] Y. Zhang, R. Springfield, S. Chen et al., " $\alpha$-GalCer and iNKT cell-based cancer immunotherapy: realizing the therapeutic potentials," Frontiers in Immunology, vol. 10, 2019.

[138] F. Fais, C. Tenca, G. Cimino et al., "CD1d expression on Bprecursor acute lymphoblastic leukemia subsets with poor prognosis," Leukemia, vol. 19, pp. 551-556, 2005.

[139] A. Bojarska-Junak, M. Waldowska, J. Woś et al., "Intracellular IL-4 and IFN- $\gamma$ expression in iNKT cells from patients with chronic lymphocytic leukemia," Oncology Letters, vol. 15, pp. 1580-1590, 2017.

[140] A. Rossignol, A. Levescot, F. Jacomet et al., "Evidence for BCR-ABL-dependent dysfunctions of iNKT cells from chronic myeloid leukemia patients," European Journal of Immunology, vol. 42, pp. 1870-1875, 2012.

[141] R. Weinkove, C. R. Brooks, J. M. Carter, I. F. Hermans, and F. Ronchese, "Functional invariant natural killer T-cell and CD1d axis in chronic lymphocytic leukemia: implications for immunotherapy," Haematologica, vol. 98, no. 3, pp. 376-384, 2013.

[142] P. Dellabona, G. Casorati, C. de Lalla, D. Montagna, and F. Locatelli, "On the use of donor-derived iNKT cells for adoptive immunotherapy to prevent leukemia recurrence in pediatric recipients of HLA haploidentical HSCT for hematological malignancies," Clinical Immunology, vol. 140, no. 2, pp. 152-159, 2011.

[143] G. Casorati, C. de Lalla, and P. Dellabona, "Invariant natural killer $\mathrm{T}$ cells reconstitution and the control of leukemia relapse in pediatric haploidentical hematopoietic stem cell transplantation," OncoImmunology, vol. 1, pp. 355-357, 2014.

[144] A. E. Najera Chuc, L. A. M. Cervantes, F. P. Retiguin, J. V. Ojeda, and E. R. Maldonado, "Low number of invariant NKT cells is associated with poor survival in acute myeloid leukemia," Journal of Cancer Research and Clinical Oncology, vol. 138, pp. 1427-1432, 2012.

[145] M. V. Dhodapkar and V. Kumar, "Type II NKT cells and their emerging role in health and disease," The Journal of Immunology, vol. 198, pp. 1015-1021, 2017.
[146] L. Nours, D. M. Andrews, A. P. Uldrich, J. Rossjohn, and D. I. Godfrey, "Unconventional T cell targets for cancer immunotherapy," Immunity, vol. 48, no. 3, pp. 453-473, 2018.

[147] M. Terabe and J. A. Berzofsky, "Tissue-specific roles of NKT cells in tumor immunity," Frontiers in Immunology, vol. 9, pp. 1-11, 2018.

[148] M. Blomqvist, S. Rhost, S. Teneberg et al., "Multiple tissuespecific isoforms of sulfatide activate CD1d-restricted type II NKT cells," European Journal of Immunology, vol. 39, pp. 1726-1735, 2014.

[149] P. Arrenberg, R. Halder, Y. Dai, I. Maricic, and V. Kumar, "Oligoclonality and innate-like features in the TCR repertoire of type II NKT cells reactive to a-linked self-glycolipid," Proceedings of the National Academy of Sciences, vol. 107, no. 24, pp. 10984-10989, 2010.

[150] A. K. Singh, P. Tripathi, and S. L. Cardell, "Type II NKT cells: an elusive population with immunoregulatory properties," Frontiers in Immunology, vol. 9, p. 1969, 2018.

[151] D. I. Godfrey and M. Kronenberg, "Going both ways: immune regulation via CD1d-dependent NKT cells," Journal of Clinical Investigation, vol. 114, pp. 1379-1388, 2004.

[152] J. Le Nours, A. Shahine, and S. Gras, "Molecular features of lipid-based antigen presentation by group 1 CD1 molecules," Seminars in Cell \& Developmental Biology, vol. 84, pp. 48-57, 2018.

[153] M. Consonni, C. de Lalla, A. Bigi, P. Dellabona, and G. Casorati, "Harnessing the CD1 restricted T cell response for leukemia adoptive immunotherapy," Cytokine \& Growth Factor Reviews, vol. 36, pp. 117-123, 2017.

[154] S. Porcelli, C. E. Yockey, M. B. Brenner, and S. P. Balk, "Analysis of $\mathrm{T}$ cell antigen receptor (TCR) expression by human peripheral blood CD4-8- alpha/beta $\mathrm{T}$ cells demonstrates preferential use of several $\mathrm{V}$ beta genes and an invariant TCR alpha chain," Journal of Experimental Medicine, vol. 178, pp. 1-16, 1993.

[155] O. Lantz and A. Bendelac, "An invariant T cell receptor alpha chain is used by a unique subset of major histocompatibility complex class I-specific CD4+ and CD4-8- T cells in mice and humans," Journal of Experimental Medicine, vol. 180, pp. 1097-1106, 1994.

[156] F. Tilloy, E. Treiner, S.-H. Park et al., “An invariant T cell receptor $\alpha$ chain defines a novel TAP-independent major histocompatibility complex class Ib-restricted $\alpha / \beta$ T cell subpopulation in mammals," Journal of Experimental Medicine, vol. 189, pp. 1907-1921, 1999.

[157] E. Treiner, L. Duban, S. Bahram et al., "Selection of evolutionarily conserved mucosal-associated invariant $\mathrm{T}$ cells by MR1," Nature, vol. 422, pp. 164-169, 2003.

[158] H. Yamaguchi, M. Hirai, Y. Kurosawa, and K. Hashimoto, “A highly conserved major histocompatibility complex class Irelated gene in mammals," Biochem Biophys Res Commun, vol. 238, pp. 697-702, 1997.

[159] S. B. G. Eckle, A. J. Corbett, A. N. Keller et al., "Recognition of vitamin B precursors and byproducts by mucosal associated invariant T cells," Journal of Biological Chemistry, vol. 290, pp. 30204-30211, 2015.

[160] A. J. Corbett, S. B. G. Eckle, R. W. Birkinshaw et al., “Tcell activation by transitory neo-antigens derived from distinct microbial pathways," Nature, vol. 509, pp. 361-365, 2014. 
[161] E. Martin, E. Treiner, L. Duban et al., "Stepwise development of MAIT cells in mouse and human," PLoS Biology, vol. 7, article e1000054, 3 pages, 2009.

[162] N. Seach, L. Guerri, L. Le Bourhis et al., "Double positive thymocytes select mucosal-associated invariant T cells," Journal of Immunology, vol. 191, no. 12, pp. 6002-6009, 2013.

[163] H.-F. Koay, N. A. Gherardin, A. Enders et al., "A three-stage intrathymic development pathway for the mucosalassociated invariant T cell lineage," Nature Immunology, vol. 17, pp. 1300-1311, 2016.

[164] N. A. Gherardin, L. Loh, L. Admojo et al., "Enumeration, functional responses and cytotoxic capacity of MAIT cells in newly diagnosed and relapsed multiple myeloma," Scientific Reports, vol. 8, p. 4159, 2018.

[165] D. I. Godfrey, H.-F. Koay, J. McCluskey, and N. A. Gherardin, "The biology and functional importance of MAIT cells," Nature Immunology, vol. 20, no. 9, pp. 1110-1128, 2019.

[166] A. Rahimpour, H. F. Koay, A. Enders et al., "Identification of phenotypically and functionally heterogeneous mouse mucosal-associated invariant T cells using MR1 tetramers," Journal of Experimental Medicine, vol. 212, pp. 1095-1108, 2015.

[167] R. Reantragoon, A. J. Corbett, I. G. Sakala et al., "Antigenloaded MR1 tetramers define T cell receptor heterogeneity in mucosal-associated invariant T cells," Journal of Experimental Medicine, vol. 210, pp. 2305-2320, 2013.

[168] A. Toubal, I. Nel, S. Lotersztajn, and A. Lehuen, "Mucosalassociated invariant T cells and disease," Nature Reviews Immunology, vol. 19, pp. 643-657, 2019.

[169] M. Dusseaux, E. Martin, N. Serriari et al., "Human MAIT cells are xenobiotic-resistant, tissue-targeted, CD161hi IL17-secreting T cells," Blood, vol. 117, pp. 1250-1259, 2011.

[170] J. E. Ussher, M. Bilton, E. Attwod et al., "CD161 ++ CD8 + T cells, including the MAIT cell subset, are specifically activated by IL-12+IL-18 in a TCR-independent manner," European Journal of Immunology, vol. 44, pp. 195-203, 2014.

[171] S. M. M. Haeryfar, C. R. Shaler, and P. T. Rudak, "Mucosaassociated invariant $\mathrm{T}$ cells in malignancies: a faithful friend or formidable foe?," Cancer Immunol Immunother, vol. 67, pp. 1885-1896, 2018.

[172] N.-E. Serriari, M. Eoche, L. Lamotte et al., "Innate mucosalassociated invariant T (MAIT) cells are activated in inflammatory bowel diseases," Clinical \& Experimental Immunology, vol. 176, pp. 266-274, 2014.

[173] T. Leng, H. D. Akther, C.-P. Hackstein et al., "TCR and inflammatory signals tune human MAIT cells to exert specific tissue repair and effector functions," Cell Reports, vol. 28, pp. 3077-3091.e5, 2019.

[174] M. Salio, O. Gasser, C. Gonzalez-Lopez et al., "Activation of human mucosal-associated invariant $\mathrm{T}$ cells induces CD40L-dependent maturation of monocyte-derived and primary dendritic cells," The Journal of Immunology, vol. 199, pp. 2631-2638, 2017.

[175] A. Kurioka, J. E. Ussher, C. Cosgrove et al., "MAIT cells are licensed through granzyme exchange to kill bacterially sensitized targets," Mucosal Immunology, vol. 8, pp. 429-440, 2015.

[176] L. Ling, Y. Lin, W. Zheng et al., "Circulating and tumorinfiltrating mucosal associated invariant T (MAIT) cells in colorectal cancer patients," Scientific Reports, vol. 6, article 20358, 2016.
[177] E. J. Won, J. K. Ju, Y.-N. Cho et al., "Clinical relevance of circulating mucosal-associated invariant $\mathrm{T}$ cell levels and their anti-cancer activity in patients with mucosal-associated cancer," Oncotarget, vol. 7, pp. 76274-76290, 2016.

[178] P. Sundström, F. Ahlmanner, P. Akéus et al., "Human mucosa-associated invariant $\mathrm{T}$ cells accumulate in colon adenocarcinomas but produce reduced amounts of IFN- $\gamma$," Journal of Immunology, vol. 195, pp. 3472-3481, 2015.

[179] J. Yan, S. Allen, E. McDonald et al., "MAIT cells promote tumor initiation, growth, and metastases via tumor MR1," Cancer Discovery, vol. 10, pp. 124-141, 2020.

[180] M. Favreau, K. Venken, S. Faict et al., "Both mucosalassociated invariant and natural killer T-cell deficiency in multiple myeloma can be countered by PD-1 inhibition," Haematologica, vol. 102, pp. e266-e270, 2017.

[181] M. Lepore, A. Kalinichenko, S. Calogero et al., "Functionally diverse human $\mathrm{T}$ cells recognize non-microbial antigens presented by MR1," Elife, vol. 6, 2017.

[182] M. D. Crowther, G. Dolton, M. Legut et al., "Genome-wide CRISPR-Cas9 screening reveals ubiquitous T cell cancer targeting via the monomorphic MHC class I-related protein MR1," Nature Immunology, vol. 21, pp. 178-185, 2020.

[183] E. W. Meermeier, B. F. Laugel, A. K. Sewell et al., "Human TRAV1-2-negative MR1-restricted T cells detect S. pyogenes and alternatives to MAIT riboflavin-based antigens," Nature Communications, vol. 7, article 12506, 2016.

[184] N. A. Gherardin, A. N. Keller, R. E. Woolley et al., "Diversity of T cells restricted by the MHC class I-related molecule MR1 facilitates differential antigen recognition," Immunity, vol. 44, pp. 32-45, 2016.

[185] K. Wu, J. Feng, Y. Xiu et al., "V $\delta 2$ T cell subsets, defined by PD-1 and TIM-3 expression, present varied cytokine responses in acute myeloid leukemia patients," International Immunopharmacology, vol. 80, article 106122, 2020.

[186] T. Hoeres, E. Holzmann, M. Smetak, J. Birkmann, and M. Wilhelm, "PD-1 signaling modulates interferon- $\gamma$ production by gamma delta $(\gamma \delta)$ T-cells in response to leukemia," Oncoimmunology, vol. 8, 2018.

[187] K. Durgan, M. Ali, P. Warner, and Y. E. Latchman, “Targeting NKT cells and PD-L1 pathway results in augmented anti-tumor responses in a melanoma model," Cancer Immunol Immunother, vol. 60, pp. 547-558, 2011.

[188] I. Melero, D. M. Berman, M. A. Aznar, A. J. Korman, J. L. P. Gracia, and J. Haanen, "Evolving synergistic combinations of targeted immunotherapies to combat cancer," Nature Reviews Cancer, vol. 15, pp. 457-472, 2015.

[189] S. K. Tasian, "Acute myeloid leukemia chimeric antigen receptor T-cell immunotherapy: how far up the road have we traveled?," Therapeutic Advances in Hematology, vol. 9, pp. 135-148, 2018.

[190] E. Jacoby, S. A. Shahani, and N. N. Shah, "Updates on CAR T-cell therapy in B-cell malignancies," Immunological Reviews, vol. 290, pp. 39-59, 2019.

[191] A. I. Salter, M. J. Pont, and S. R. Riddell, "Chimeric antigen receptor-modified T cells: CD19 and the road beyond," Blood, vol. 131, pp. 2621-2629, 2018.

[192] D. Cortés-Selva, B. Dasgupta, S. Singh, and I. S. Grewal, "Innate and innate-like cells: the future of chimeric antigen receptor (CAR) cell therapy," Trends in Pharmacological Sciences, vol. 42, pp. 45-59, 2020. 